\title{
Machine Learning to Estimate Surface Roughness from Satellite Images
}

\author{
Abhilash Singh (D), Kumar Gaurav*(D), Atul Kumar Rai (D) and Zafar Beg (D) \\ Fluvial Geomorphology and Remote Sensing Laboratory, Department of Earth and Environmental Sciences, \\ Indian Institute of Science Education and Research Bhopal, Bhopal 462066, India; \\ sabhilash@iiserb.ac.in (A.S.); atulk@iiserb.ac.in (A.K.R.); zafar17@iiserb.ac.in (Z.B.) \\ * Correspondence: kgaurav@iiserb.ac.in
}

Citation: Singh, A.; Gaurav K.; Rai, A.K.; Beg, Z. Machine Learning to Estimate Surface Roughness from Satellite Images. Remote Sens. 2021, 13, 3794. https://doi.org/10.3390/ rs13193794

Academic Editor: Francesco Mattia

Received: 13 July 2021

Accepted: 8 September 2021

Published: 22 September 2021

Publisher's Note: MDPI stays neutral with regard to jurisdictional claims in published maps and institutional affiliations.

Copyright: (c) 2021 by the authors. Licensee MDPI, Basel, Switzerland. This article is an open access article distributed under the terms and conditions of the Creative Commons Attribution (CC BY) license (https:/ / creativecommons.org/licenses/by/ $4.0 /)$.
Abstract: We apply the Support Vector Regression (SVR) machine learning model to estimate surface roughness on a large alluvial fan of the Kosi River in the Himalayan Foreland from satellite images. To train the model, we used input features such as radar backscatter values in Vertical-Vertical (VV) and Vertical-Horizontal (VH) polarisation, incidence angle from Sentinel-1, Normalised Difference Vegetation Index (NDVI) from Sentinel-2, and surface elevation from Shuttle Radar Topographic Mission (SRTM). We generated additional features (VH/VV and VH-VV) through a linear data fusion of the existing features. For the training and validation of our model, we conducted a field campaign during 11-20 December 2019. We measured surface roughness at 78 different locations over the entire fan surface using an in-house-developed mechanical pin-profiler. We used the regression tree ensemble approach to assess the relative importance of individual input feature to predict the surface soil roughness from SVR model. We eliminated the irrelevant input features using an iterative backward elimination approach. We then performed feature sensitivity to evaluate the riskiness of the selected features. Finally, we applied the dimension reduction and scaling to minimise the data redundancy and bring them to a similar level. Based on these, we proposed five SVR methods (PCA-NS-SVR, PCA-CM-SVR, PCA-ZM-SVR, PCA-MM-SVR, and PCA-S-SVR). We trained and evaluated the performance of all variants of SVR with a 60:40 ratio using the input features and the in-situ surface roughness. We compared the performance of SVR models with six different benchmark machine learning models (i.e., Gaussian Process Regression (GPR), Generalised Regression Neural Network (GRNN), Binary Decision Tree (BDT), Bragging Ensemble Learning, Boosting Ensemble Learning, and Automated Machine Learning (AutoML)). We observed that the PCA-MM-SVR perform better with a coefficient of correlation $(\mathrm{R}=0.74)$, Root Mean Square Error $($ RMSE $=0.16 \mathrm{~cm})$, and Mean Square Error $\left(\right.$ MSE $\left.=0.025 \mathrm{~cm}^{2}\right)$. To ensure a fair selection of the machine learning model, we evaluated the Akaike's Information Criterion (AIC), corrected AIC (AICc), and Bayesian Information Criterion (BIC). We observed that SVR exhibits the lowest values of AIC, corrected AIC, and BIC of all the other methods; this indicates the best goodness-of-fit. Eventually, we also compared the result of PCA-MM-SVR with the surface roughness estimated from different empirical and semi-empirical radar backscatter models. The accuracy of the PCA-MM-SVR model is better than the backscatter models. This study provides a robust approach to measure surface roughness at high spatial and temporal resolutions solely from the satellite data.

Keywords: surface roughness; Sentinel-1; Sentinel-2; machine learning models; AutoML; backscatter models

\section{Introduction}

Surface soil roughness is an important parameter in many environmental applications, such as: agronomy, geomorphology, hydrology, meteorology, and climate change modeling [1,2]. By definition, surface roughness is a non-zero Gaussian random process that is parameterised by the Root Mean Square (RMS) height (s), and correlation length 
(l). The root mean square height describes the vertical roughness, whereas the correlation length is used to describe roughness at a horizontal scale. Usually, surface roughness measured in the horizontal scale is subject to large variability and uncertainty as compared to the vertical scale [3]. This is probably one reason that RMS height is used in the inversion of various backscattering models [4]. The surface roughness (RMS height) is considered a highly sensitive parameter in modeling soil moisture from the Synthetic Aperture Radar (SAR) images [5]. It is important to have an accurate measurement of surface roughness in order to model the soil moisture from SAR images [6].

Surface soil roughness can be categorised into four different scales, such as the microrelief, random, oriented roughness, and higher-order roughness [7]. The microrelief roughness is due to individual grains. The random roughness is due to natural changes such as soil cloudiness and weather conditions (rainfall, freeze). The oriented roughness is due to tillage operations. The higher-order roughness is due to elevation variation $[8,9]$. Generally oriented or high-order surface roughness is required in various backscatter models to estimate soil moisture from SAR images [10,11].

At the field scale, surface soil roughness can be measured using contact methods (i.e., roller chain and pin profilometer) or sensor methods (i.e., stereo-photogrammetry and laser scanning). The selection of an appropriate method depends on the field conditions, accuracy, and spatial resolution [12]. The roller chain method is based on the principle that, for a given chain length, the horizontal distance covered by the chain decreases as the surface roughness increases. This method is fast and requires little training, but overestimates the surface soil roughness [12,13]. A pin-profiler measures the surface roughness by tracing the one-dimensional surface profile from the relative position of pins placed vertically on the ground. This method is economical and provides acceptable accuracy for microwave remote-sensing applications, but it is time-consuming and requires physical contact with the surface [14-18]. In the stereo-photogrammetry technique, the DEM is calculated from two digital images acquired with $70 \%$ overlap of the same area. This method is economical, but the accuracy of the result highly depends on the data-processing algorithms [19]. The laser scanner approach uses optical triangulation technique using the laser beams to measure surface elevation automatically. It measures surface roughness precisely at high spatial resolution. It is time-consuming and often not recommended for extensive field campaigns [20].

Recently, active microwave remote-sensing images have been widely used to measure surface features at regional and local scales [21-23]. The microwave signal is highly sensitive to both geometric and dielectric properties of the soil. These properties are interlinked and often studied concurrently. The dielectric properties of the soil are sensitive to the texture, moisture, temperature, and bulk density of the soil. The geometric properties of soil correspond to the physical surface roughness [24]. The variation in the dielectric constant produces a "dielectric roughness effect" apart from the physical roughness. This effect is significant during the drying-out of the soil [25].

SAR images have significantly improved the measurement and estimation of soil attributes. Several studies are conducted to estimate surface soil moisture through various empirical, semi-empirical, and theoretical backscattering models [26-33]. These backscattering models require quad-polarised SAR images and mostly applicable to barren and agricultural lands. Shi et al. [34,35] were probably the first to estimate surface soil roughness from SAR images. They inverted the Integral Equation Method (IEM) model to estimate surface soil roughness from quad-polarised L-band Airborne SAR operated by the Jet Propulsion Laboratory (AIRSAR) and Spaceborne Imaging Radar-C (SIR-C) data. They reported surface roughness, estimated from the inversion of the IEM model, accord well with the in-situ measured values for barren and spare vegetated fields with an RMSE of $1.9 \mathrm{~dB}$. Baghdadi et al. [36] used SAR images (RADARSAT and ERS) of various incidence angles to estimate surface soil roughness. They reported that surface soil roughness is highly sensitive to the incidence angle, and a higher incidence angle $\left(>45^{\circ}\right)$ is more suitable for differentiating various surface roughness classes over bare agricultural plots. Zribi et al. [37] 
proposed a semi-empirical model to estimate surface soil roughness over a heterogeneous terrain. They validated their model using the results of the IEM single-scattering model. They found a good correlation between these models for small- or medium-range surface roughness with incidence angle $\left(>35^{\circ}\right)$. Their model accurately estimates the surface roughness over the homogeneous surface and overestimates in the region characterised by a high degree of roughness. Rahman et al. [38], applied the IEM model on Envisat ASAR images to estimate surface roughness and soil moisture. Baghdadi et al. [39] proposed an inversion model based on multi-layer perceptron to estimate soil parameters using C-band SAR data over bare agricultural plots. They trained the neural network model using simulated datasets generated from IEM models over a valid range of input parameters. They reported a precision of $0.5 \mathrm{~cm}$ (RMSE) for surface soil roughness below $2 \mathrm{~cm}$. Sawada et al. [40] proposed a novel algorithm to retrieve the surface soil roughness through a fusion of SAR and optical data. They fused the Moderate Resolution Imaging Spectroradiometer (MODIS) and Advanced Microwave Scanning Radiometer 2 (AMSR2) data to determine surface roughness through the radiative transfer model. Baghdadi et al. [4] proposed an inversion technique to estimate the surface soil roughness from Sentinel-1 images. They generated synthetic data by training a neural network model through IEM model simulations. More recently, Mirmazloumi et al. [41] proposed a new empirical model to estimate surface soil attributes (i.e., soil moisture and surface roughness) from AIRSAR and RADARSAT-1 images.

Zribi and Dechambre [42] proposed an empirical model to estimate surface soil roughness by using two SAR images acquired at different incidence angles. They selected a small incidence angle, i.e., $23^{\circ}$ and a large incidence angle, i.e., $39^{\circ}$ to estimate the surface soil roughness. Srivastava et al. [43] proposed an empirical regression model to estimate surface soil roughness from SAR (Envisat-1) images. They observed that the linear data fusion of $\mathrm{VH}$ and VV in the form of VH-VV polarisation is more sensitive to surface soil roughness. Later, Marzahn et al. [24] proposed a novel approach to estimate surface roughness over an agricultural field using a photogrammetric acquisition system. They generated the surface models from digital images. They reported that RMS roughness of $s \leq 2$ could reliably be estimated from a $2 \mathrm{~m}^{2}$ acquisition areas. Recently, Ullmann and Stauch [44] evaluated the relationship between the various mono- and multi-temporal Sentinel-1 (SAR) features with the surface soil roughness. They concluded that the surface soil roughness is more sensitive to the vertical variation of the profile than the horizontal. More recently, Azizi et al. [45] developed a computerised approach to estimate surface soil roughness based on the stereo vision technique. They computed the elevation component to reconstruct the 3-D model of the images taken from the field.

Accurate estimates of surface roughness through backscattering models are mainly limited by the model assumptions. All the studies discussed above assume ideal soil characteristics. Under this assumption, the soil roughness is explainable by a single-scale stationary process (i.e., parameters do not change over time). Such assumptions are overruled due to the complex geometry of inherent soil surface [3]. Furthermore, most of the backscattering models are validated at fine scales under a controlled environment $[46,47]$. They do not accord well over a region that exhibits large intra-field variability.

To overcome the issues with the existing methods, we propose a novel machinelearning approach to predict surface soil roughness solely from the publicly available remote-sensing data. We trained thirty-five variants of seven different machine-learning algorithms using relevant features and in-situ-measured surface roughness. We extract these features from Sentinel-1, Sentinel-2, and SRTM data. Once the models are trained, we evaluated their performance using robust performance metrics in terms of their accuracy and computational time complexity. Finally, we used the best model to generate a surface roughness map. 


\section{Site Characteristics}

We conducted this study on a large alluvial fan of the Kosi River on the Himalayan Foreland in north Bihar plain, India. This fan has been active since the Holocene, and resulted from the gradual migration of the Kosi River. During this process, the Kosi River deposited its sediment, carried from the Himalayas, and built a large conical sedimentary structure, the Kosi Fan [48-51]. The Kosi Fan is one of the largest fluvial fans, built over an area approximately $10,351 \mathrm{~km}^{2}$, and has a radius of about $115-150 \mathrm{~km} \mathrm{[48,51].} \mathrm{Its} \mathrm{surface} \mathrm{is}$ composed of homogeneous quartz sediments with a median grain size, varying in a range from $300 \mu \mathrm{m}$ in its proximal to about $100 \mu \mathrm{m}$ in the distal part [51,52]. The dominant soil types are sandy, sandy loam, loam, and silty loam. The aerial view of the Kosi fan appears nearly conical. Elevation of the Kosi Fan from the mean sea level varies between $110 \mathrm{~m}$ and $80 \mathrm{~m}$ in the proximal and $50 \mathrm{~m}$ and $30 \mathrm{~m}$ in the distal part. The surface slope varies gently from $8 \times 10^{-4}$ at the apex to $6 \times 10^{-5}$ near the toe [51].

About $84 \%$ of the total fan area is agricultural lands, $9 \%$ wetlands and water bodies, and $7 \%$ built-up [53]. The Kosi Fan is very fertile for agriculture. The agriculture is practiced in two crop seasons; the autumn (last weak of May-October) and spring (December-April), also called "Kharif" and "Rabi", respectively. The landuse, geology, grain sizes, slope, and flat terrain, together, make the Kosi Fan an ideal field site for this study.

\section{Material and Method}

\subsection{Satellite Data}

We have used Sentinel-1, Sentinel-2 satellite images, and SRTM Digital Elevation Model (DEM) to set up the machine-learning models to estimate surface roughness (Table 1). These data are freely available; they can be downloaded from the official website of European Space Agency (https:/ / scihub.copernicus.eu/; accessed on 17 December 2020) and US Geological Survey (https:/ / earthexplorer.usgs.gov; accessed on 17 December 2020) respectively. The European Space Agency (ESA) launched the Sentinel-1A (March 2014) and $-1 \mathrm{~B}$ (March 2016) satellite missions under the Copernicus program.

The Sentinel-1 (1A \& 1B) satellites consist of C-band SAR. They operate at a frequency of $5.405 \mathrm{GHz}$ and measure the uninterrupted backscattered signals from the earth's surface in all weather conditions. Depending on the soil type and moisture conditions, at this frequency, the SAR signals can penetrate up to $5 \mathrm{~cm}$ of the topsoil surface [54,55]. Sentinel-1 satellites have a temporal resolution of 12 days, that jointly (1A and $1 \mathrm{~B}$ ) result in a 6-day repeat pass over the equator [56,57]. Sentinel- 1 acquires images in four different modes: Stripmap (SM), Interferometric Wide swath (IW), Extra-Wide swath (EW), and Wave (WV). Based on the acquisition mode, they record the signals in co-polarisation (i.e., VV) or crosspolarisation (i.e., $\mathrm{VH}$ ) at $10 \mathrm{~m} \times 10 \mathrm{~m}$ cell size with $250 \mathrm{~km}$ swath. The incidence angle ranges between $29^{\circ}$ and $46^{\circ}$ in near- and far-range, respectively [56]. For our purpose, we have downloaded the dual polarised (VV \& VH) Ground Range Detected (GRD) product (Table 1). Finally, we processed the Sentinel-1 images using the Sentinel Application Platform (SNAP) v8.0 Earth Observation processing tool to obtained the backscatter values (VV and $\mathrm{VH})$. The processing steps include the radiometric calibration, multi-looking (with a multi-look factor of 6), speckle noise removal/minimising using refined Lee filter, and terrain correction. After processing, the resulting backscatter image has the cell size $60 \times 60 \mathrm{~m}$.

We downloaded Sentinel-2 images of level-2A processing (Table 1). These images are atmospherically corrected for Bottom-Of-Atmosphere (BOA) [58]. Sentinel-2, mission is a constellation of two satellites: Sentinel-2A and Sentinel-2B. They acquire images of the earth's surface in 13 spectral bands at different spatial resolutions $(10-60 \mathrm{~m})$ in the optical region of the electromagnetic spectrum. Sentinel-2 (2A and 2B) satellites have the temporal resolution 10 days that together result in a 5-day revisit period [59]. We used band $4(0.64-0.68 \mu \mathrm{m})$ and band $8(0.77-0.90 \mu \mathrm{m})$ of Sentinel-2 to obtain the NDVI. To do this, we subtracted band 5 from band 4 and divided it by the summation of band 4 and 
band 5 . The resulting NDVI image has spatial resolution $10 \times 10 \mathrm{~m}$ and its value ranges from -1 to +1 . Larger values of the NDVI represent healthy vegetation condition [60].

Table 1. Detailed specifications of Sentinel-1 and 2 images.

\begin{tabular}{|c|c|c|c|c|}
\hline \multicolumn{5}{|c|}{ Sentinel-1 } \\
\hline Date & Polarization & $\begin{array}{c}\text { Incidence Angle } \\
\left({ }^{\circ}\right)\end{array}$ & $\begin{array}{l}\text { Pixel Size } \\
(\mathrm{m} \times \mathrm{m})\end{array}$ & Direction \\
\hline 11 December 2019 & $(\mathrm{VH}, \mathrm{VV})$ & 38.6 & $10 \times 10$ & NE \\
\hline 15 December 2019 & $(\mathrm{VH}, \mathrm{VV})$ & 38.5 & $10 \times 10$ & NW \\
\hline 17 December 2019 & $(\mathrm{VH}, \mathrm{VV})$ & 38.4 & $10 \times 10$ & $\mathrm{NE}$ \\
\hline 18 December 2019 & (VH, VV) & 38.5 & $10 \times 10$ & NE \\
\hline 20 December 2019 & (VH, VV) & 38.5 & $10 \times 10$ & NW \\
\hline \multicolumn{5}{|c|}{ Sentinel-2 } \\
\hline Date & $\begin{array}{l}\text { Orbit number } \\
\text { and direction }\end{array}$ & Band & $\begin{array}{l}\text { Wavelength } \\
\text { (nm) }\end{array}$ & $\begin{array}{l}\text { Spatial Resolution } \\
\text { (m) }\end{array}$ \\
\hline 9 December 2019 & 76, Descending & 4 & $646-685$ & 10 \\
\hline 9 December 2019 & 76, Descending & 8 & 774-907 & 10 \\
\hline
\end{tabular}

To know the elevation and topography of the study area, we used a DEM obtained from the SRTM. This mission was launched in February 2000 in a joint venture between NASA, the National Geospatial-Intelligence Agency, and the German and Italian Space Agencies, with the objective to generate a high-resolution DEM of the Earth [61]. SRTM employed two synthetic aperture radars, $C(\lambda=5.6 \mathrm{~cm})$ and $X$-band system $(\lambda=3.1 \mathrm{~cm})$. It provides the earth surface elevation sampled over a grid of $1 \times 1$ arc sec $(30 \times 30 \mathrm{~m})$ and about $15 \mathrm{~m}$ vertical accuracy [62,63]. These data are freely available in the public domain and can be downloaded from the official website of the US Geological Survey (https:/ / earthexplorer.usgs.gov/; accessed on 17 December 2020).

\subsection{In-Situ Measurement}

In a field campaign during 11-20 December 2019, we measured the RMS surface roughness (s) at 78 different locations on the Kosi Fan (Figure 1). To measure surface roughness, we designed a one-dimensional pin-profiler (Figure 2a). This is a rectangular iron frame of length $=115 \mathrm{~cm}$, width $=106 \mathrm{~cm}$, and height $=105 \mathrm{~cm}$. At one end along the width, a whiteboard (width $=106 \mathrm{~cm}$ and height $=65 \mathrm{~cm}$ ) is attached with the help of two thin metal strips welded on either side to the arms of the frame. These strips have 100 holes (each $6 \mathrm{~mm}$ ) at a regular spacing of $1 \mathrm{~cm}$. They are used to place the aluminium pins (diameter $=5 \mathrm{~mm}$ and length $=60 \mathrm{~cm}$ ) so that they can freely move vertically. The top end of these pins is painted in red, and the other end is made flat. This helps to clearly detect the position of pins on the board and also prevent them from pricking into the ground at the bottom end. A metal scale is attached vertically at the margin of the whiteboard by calibrating the instrument over a perfectly smooth surface. When this instrument is placed on the earth surface, these pins will adjust themselves according to the surface undulation. The amount of undulation can be measured by reading the position of each pin on the scale. 


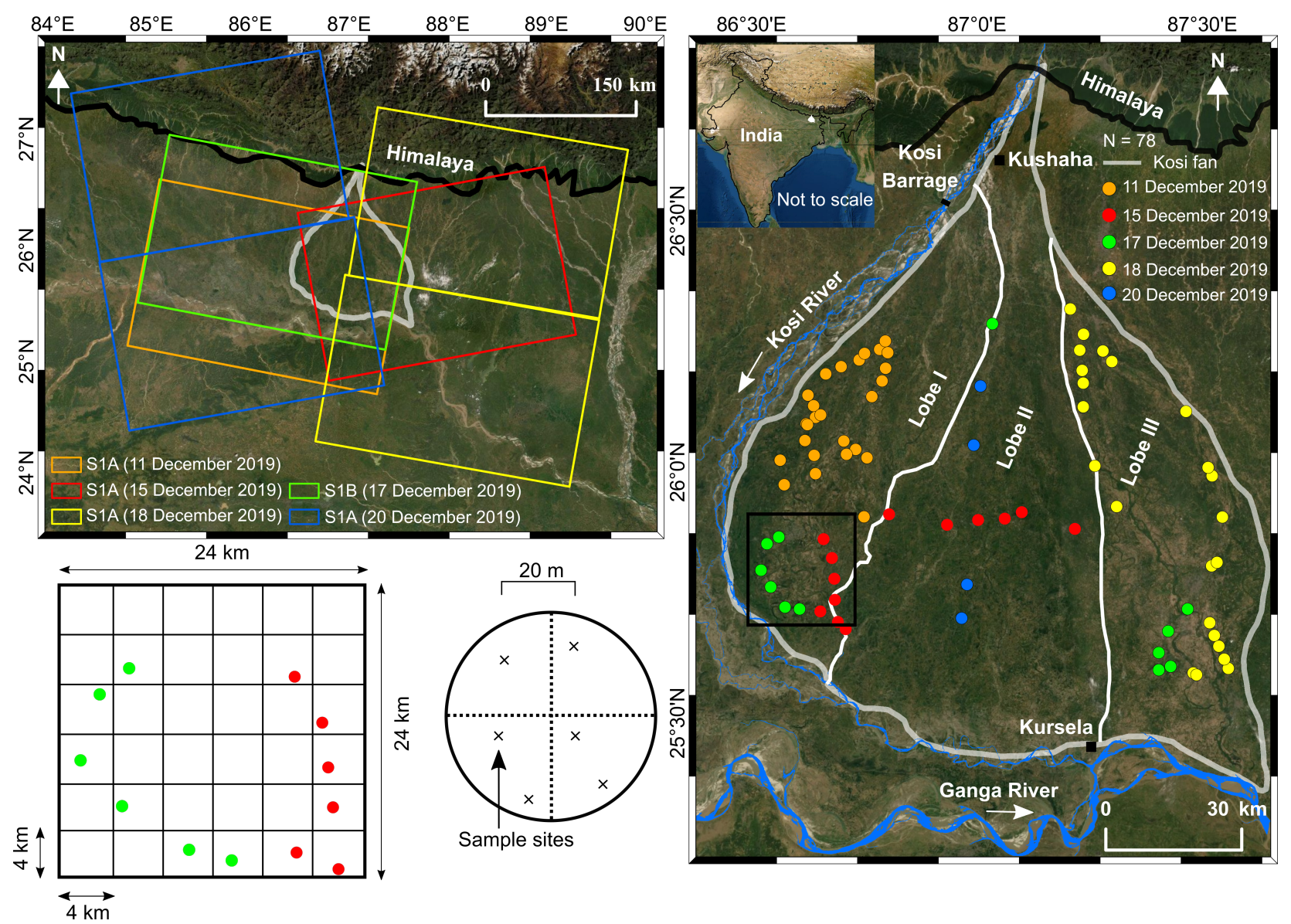

Figure 1. Image in the top left shows the location of the Kosi megafan in the Himalayan Foreland, India. The rectangles in different colours represent the Sentinel- 1 footprints on different dates during the field campaign. Image in the right shows the Kosi Fan boundary and locations of in-situ measurements in the field. Circles in different colours show the measurements locations on different dates. Grids in the bottom left illustrate the random sampling strategy for the measurements.
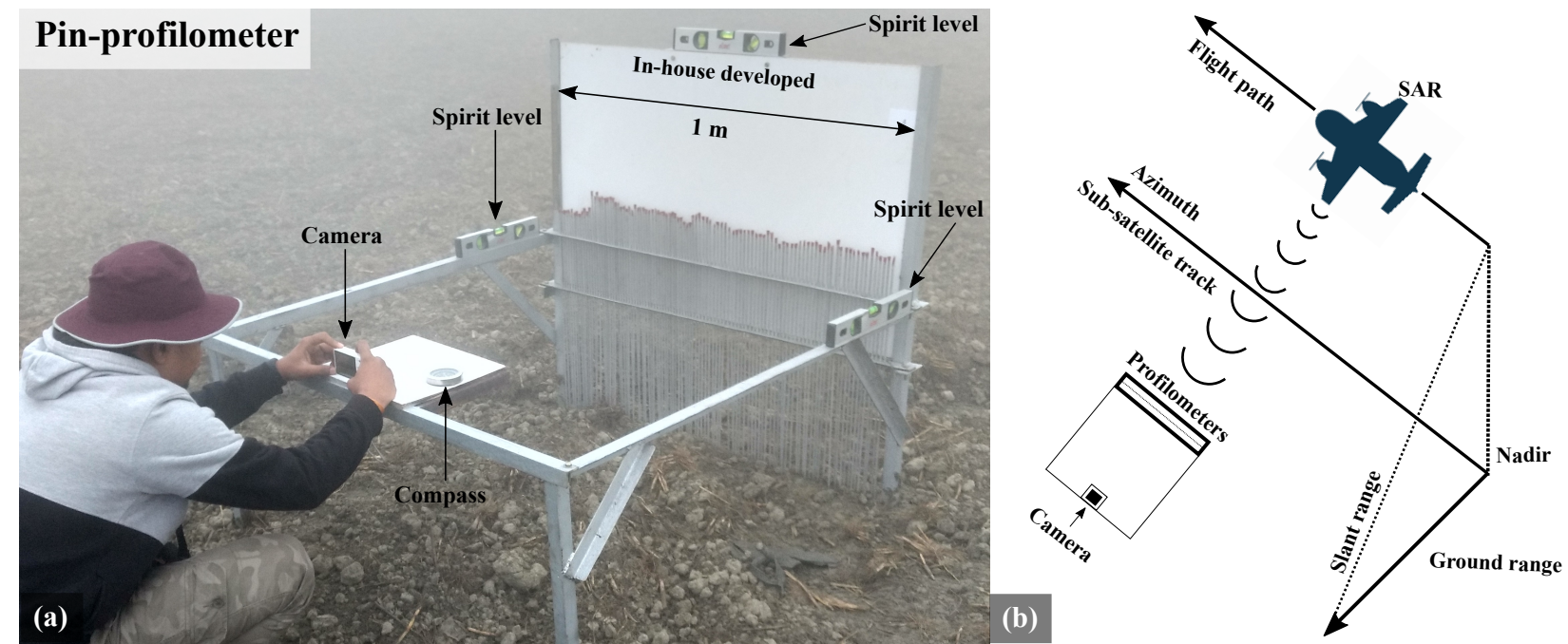

Figure 2. (a) Pin-profilometer used to measure surface roughness in the field. (b) schematic on the top right illustrates the acquisition direction of the Sentinel-1 satellite sensor. Surface roughness is measured in the field by keeping the profile-meter parallel to the direction of the satellite.

In the field, we used the random grid sampling approach to measure the in-situ surface roughness. We divided the study area into several square grids of size $4 \mathrm{~km} \times 4 \mathrm{~km}$ each (Figure 1). The circles marked in different colors (Figure 1) represent an average 
surface roughness value from 3 to 5 sampling sites (within a pixel size of the Sentinel-1) that are separated at least $20 \mathrm{~m}$ from each other. This is done to incorporate the effect of any spatial heterogeneity (variation) present at the length scale of a two-dimensional satellite pixel (i.e., $60 \mathrm{~m}$ ). This minimises the measurement uncertainty and enables direct pointto-pixel comparison for training and testing the machine learning model [64,65]. Further, to measure surface roughness, we placed the pin-profiler at the location on the ground where surface roughness has to be recorded. We leveled the instrument properly using spirit levels on the two arms and on the top of the whiteboard to avoid any unintentional tilt (Figure 2a). While conducting measurements, we ensure that the pin-profiler is placed parallel to the acquisition direction of the Sentinel-1 satellite (Figure 2b). This ensures that we are measuring the same surface that is illuminated and recorded by the satellite sensors. This process ensures the qualitative measurements of surface roughness in terms of measurement directions. We have reported the directions for all the in-situ sites in Table A1. Once the instrument is laid over the surface, the pins are gently released until they touch the top surface. We take photographs by keeping the camera horizontal at the frame arm located in front of the whiteboard to capture the undulation of the pin's position. We record the coordinates (latitude and longitude) at each sampling location using a Garmin-64s handheld GPS. At each sampling location, we have also measured the surface soil moisture using TDR-Probe (Theta-Probe). Before taking the measurements, we have calibrated the Theta-Probe (ML3 sensor) for our field using the procedure described in Singh et al. [56].

We then process the photograph that was automatically taken to detect surface roughness in MATLAB ${ }^{\circledR}$ considering the red tip of the pin as a reference (Figure 3). In doing so, we first calibrate the image to its natural size using the scale embedded on the instrument. We identify the red tips of the pins and digitise them. Once the photographs are processed, we compute the RMS surface roughness according to:

$$
s=\sqrt{\frac{\sum\left(x_{p}-\bar{x}\right)^{2}}{n_{p}-1}}
$$

where $n_{p}$ is the number of vertical pins, $x_{p}$ is the recorded height of $p^{\text {th }}$ pin, and $\bar{x}$ is the average height. The average values of the surface roughness and measurement directions are listed in Table A1 (Appendix A). Additionally, based on these values, we have classified the roughness into four major classes on the Kosi fan: stubble field, harrowed field, ploughed field, and furrow field (Figure 4).

\subsection{Support Vector Regression}

We use SVR algorithms to estimate soil roughness from satellite images. We preferred the interpretable regression-based machine-learning algorithms over the black-box models [66]. In black-box machine learning models, the prediction processes are not clear, whereas in the interpretable models, it is clear how predictions are made. Recently, the use of interpretable models has increased in machine learning [67].

The objective of a regression-based machine learning model is to obtain mapping functions that can predict the response variables. Parameters of such mapping functions are obtained from the training data. They are the initial data used to train the algorithms by fitting and tuning the parameters of a mapping function. This is usually complemented by a set of unseen datasets called the testing data and used to validate the trained machine-learning model. The SVR models are widely used to solve various problems in earth sciences, such as real-time flood stage forecasting, snow-depth retrieval, drought prediction, and landuse/landcover change analysis. [68-76]. The SVR has an excellent generalisation capability with optimal accuracy that makes it applicable to the solution of various problems in earth sciences, image processing, wireless sensor networks, and blockchain [77-80]. 

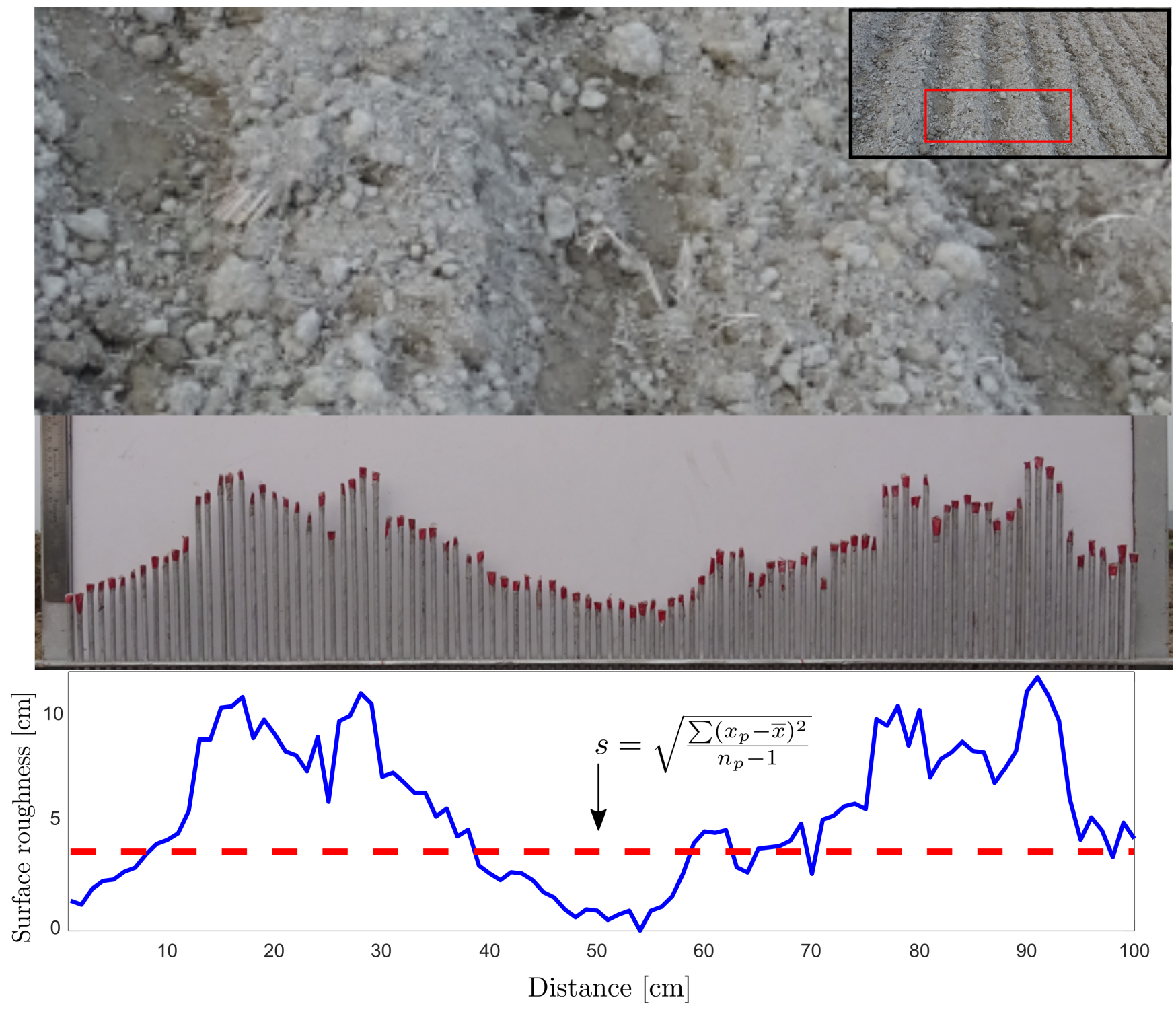

Figure 3. Surface undulation profile extracted after processing the photographs captured for the pin-profile using a digital camera in the field.

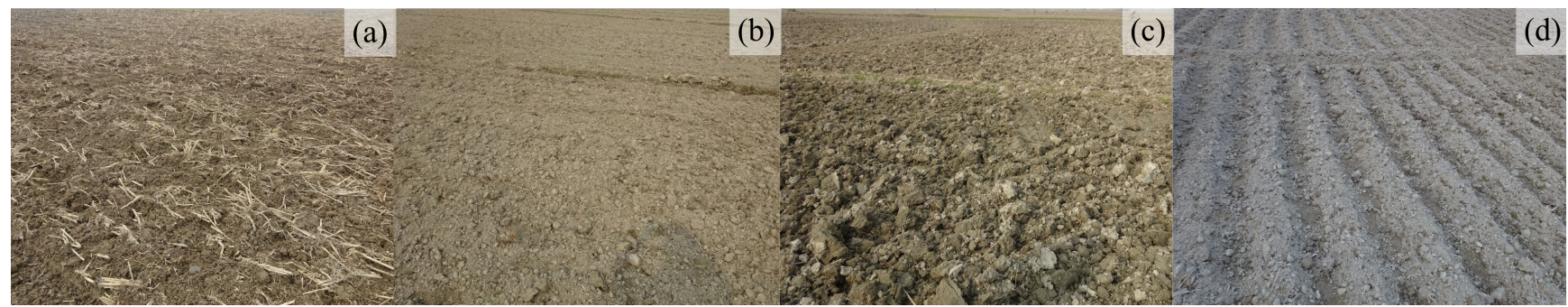

Figure 4. Field photographs to illustrate the surface roughness conditions in different agricultural plots on the Kosi Fan. (a) shows the photograph of a stubble field $(\mathrm{s}<1 \mathrm{~cm})$, (b) harrow field $(1 \mathrm{~cm} \leq \mathrm{s}<2 \mathrm{~cm})$, (c) ploughed field $(2 \mathrm{~cm} \leq \mathrm{s}<3.5 \mathrm{~cm})$, and (d) furrow field $(\mathrm{s} \geq 3.5 \mathrm{~cm})$.

Vapnik [81] introduced the support vector machine in statistical learning theory. Support vectors that deal with the regression are known as support vector regression [82]. A mathematical explanation of the SVR is provided below.

Given a sample set, $\mathrm{S}=\left[\left(x_{1}, y_{1}\right),\left(x_{2}, y_{2}\right), \ldots,\left(x_{i}, y_{i}\right), \ldots,\left(x_{N}, y_{N}\right)\right]$, where $x_{i}$ is the $N$ dimensional input data, $y_{i}$ is the corresponding output variable, and $N$ is the total samples. 
Using SVR, we can estimate the dependent variable, $y(x)$ for a given independent variable, $x$, according to Equation (2);

$$
y(x)=w^{T} \phi(x)+b
$$

where $\phi(x)$ is the high-dimensional feature spaces that are non-linearly mapped with respect to the independent variable, $x$. The coefficients $w$ and $b$ are the weight vector and bias term, respectively. The value of $w$ and $b$ are obtained by minimisation of the empirical risk function $R(C)$ according to Equation (3):

$$
R(C)=C \frac{1}{N} \sum_{i=1}^{N} L_{\epsilon}\left(y(x), y_{i}\right)+\frac{1}{2}\|w\|^{2}
$$

where $L_{\epsilon}\left(y(x), y_{i}\right)$ is the loss function (Figure $5 \mathrm{~b}$ ) given by;

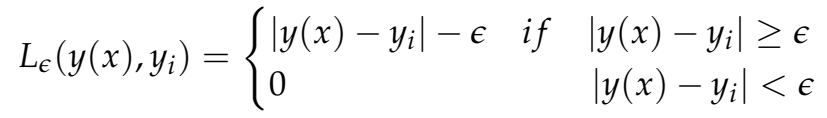

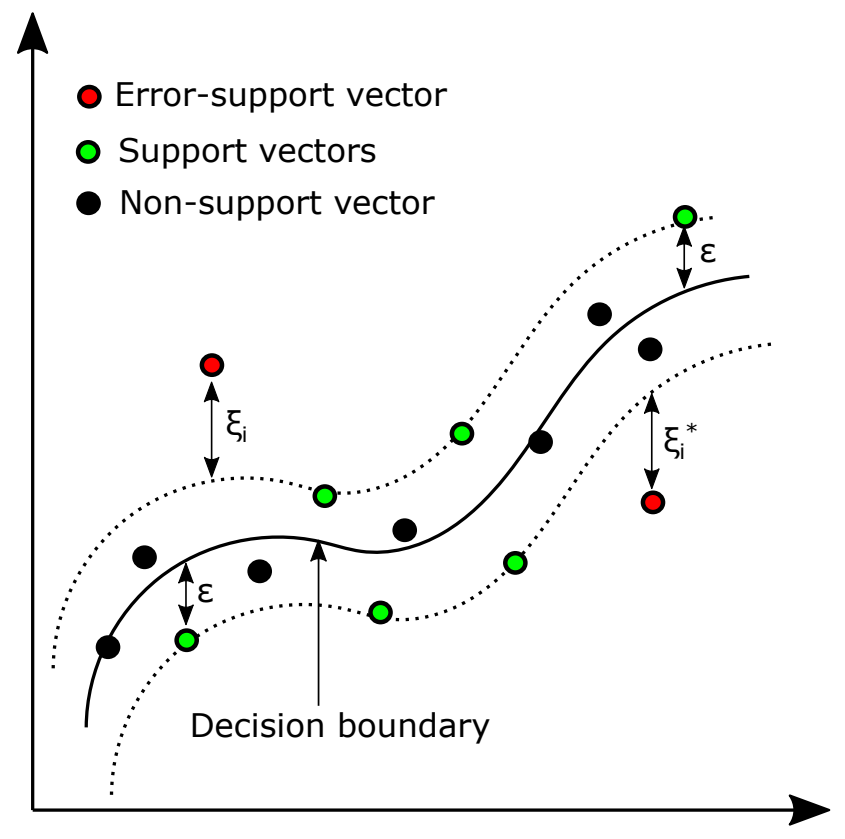

(a)

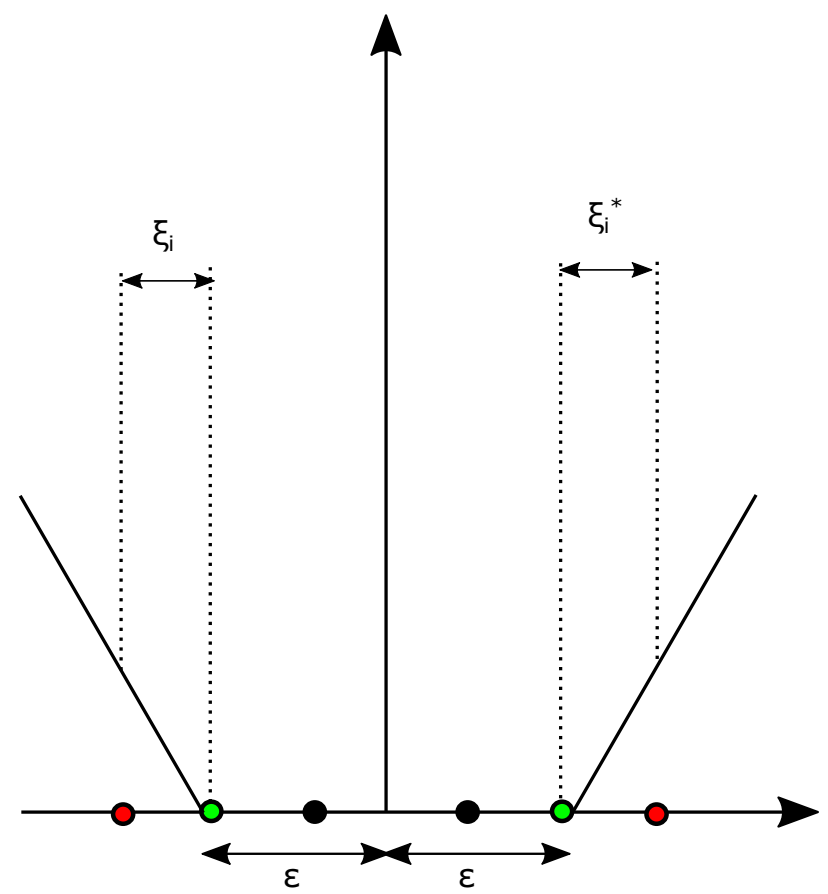

(b)

Figure 5. Schematic to illustrate (a) the conceptual structure of the support vector regression, (b) the loss function.

The risk function (Equation (3)) is modified by introducing the relaxation variables $\xi$ and $\xi^{*}$ according to:

$$
\begin{gathered}
\text { minimise : } \\
\text { subject to }=C \sum_{i=1}^{N}\left(\xi_{i}+\xi_{i}^{*}\right)+\frac{1}{2}\|w\|^{2} \\
\begin{array}{ll}
y_{i}-\left(w . \phi\left(x_{i}\right)+b\right) & \leq \epsilon+\xi_{i} \\
\left(w . \phi\left(x_{i}\right)+b\right)-y_{i} & \leq \epsilon+\xi_{i}^{*} \\
\xi_{i}, \xi_{i}^{*} & \geq 0 \\
i=1,2, \ldots, N &
\end{array}
\end{gathered}
$$

where $\epsilon$ is the loss factor and $C$ is the penalty factor. To extend the SVR for non-linear function (Figure 5a), the risk function and its constraints can be rewritten in their dual form by introducing the dual set of variables using the Lagrange function. 


$$
\begin{aligned}
& \text { minimise : } R\left(\alpha_{i}, \alpha_{i}^{*}\right)=\frac{1}{2} \sum_{i=1}^{N} \sum_{i=1}^{N}\left(\alpha_{i}-\alpha_{i}^{*}\right)\left(\alpha_{j}-\alpha_{j}^{*}\right) K+\epsilon \sum_{i=1}^{N}\left(\alpha_{i}+\alpha_{i}^{*}\right)-\sum_{i=1}^{N} y_{i}\left(\alpha_{i}-\alpha_{i}^{*}\right) \\
& \text { subject to }\left\{\begin{array}{l}
\sum_{i=1}^{N}\left(\alpha_{i}, \alpha_{i}^{*}\right)=0 \\
0 \leq \alpha_{i}, \alpha_{i}^{*} \leq C \\
i=1,2, \ldots, N
\end{array}\right.
\end{aligned}
$$

where $\alpha_{i}$ and $\alpha_{i}^{*}$ are the Lagrange multipliers and $K$ is the kernel function given according to;

$$
K=K(i, j)=\phi\left(x_{i}\right)^{T} \phi\left(x_{j}\right)
$$

We used the Homogeneous Polynomial kernel because it is a non-stationary kernel that is well-suited to standardised training data.

$$
K(i, j)=\gamma\left(x_{i} * x_{j}\right)^{d}
$$

where $\gamma$ and $d$ represent the structural parameter and degree of the Polynomial function respectively.

The final risk function for the non-linear SVR reads;

$$
y(x)=\sum_{i=1}^{N}\left(\alpha_{i}-\alpha_{i}^{*}\right) K\left(x_{i}, x_{j}\right)+b
$$

\subsubsection{Model Setup}

We setup the SVR model to estimate surface roughness. This includes feature generation from the input features, selection of training and validation data, optimisation of the training model, and finally, model evaluation. A detailed flow chart of the model setup is illustrated in Figure 6.

We identified five input features, namely incidence angle, backscatter values $\left(\sigma_{0}\right)$ Sentinel-1 for both (VH and VV) polarisation, NDVI from Sentinel-2, and elevation from the SRTM DEM. The spatial resolution of these features are different, for example; spatial resolution of the processed backscatter value $\left(\sigma_{0}\right)$ of the Sentinel-1 image is available at $60 \times 60 \mathrm{~m}, \mathrm{NDVI}$ at $10 \mathrm{~m}$, and the surface elevation at $30 \mathrm{~m}$. We applied the nearestneighbor algorithm to resample the NDVI and elevation grids at $60 \times 60 \mathrm{~m}$; a grid size comparable to the backscatter images. Finally, these input features were used to train the model and predict surface roughness. We evaluated the in-sample error (i.e., MSE) in the input features. They constitute an in-sample error of about $4 \times 10^{-15}$. Furthermore, from a linear combination/fusion of input features, we generated two more features by taking the ratio of $\mathrm{VH} / \mathrm{VV}$ and difference of $\mathrm{VH}-\mathrm{VV}$ polarisation [83]. All seven features together reduce the in-sample error (MSE) to $1.8 \times 10^{-22}$.

Now, we individually evaluate the relative importance of input features through regression tree ensemble in the prediction of surface roughness. We applied the LeastSquares Boosting (LSBoost) ensemble aggregation method with tree learner for 100 learning cycles to train the regression ensemble. We then calculated the predictor importance by adding changes in the MSE (created due to a split in the tree learner) and normalised it using the total branch nodes. The higher value of this ratio corresponds to high importance for the ensemble. Furthermore, we estimated predictive measures of association (i.e., feature association matrix) through Pearson's linear correlation approach. The input features of a machine learning model should not be highly correlated. This makes the machine learning models unstable and highly sensitive [84]. 


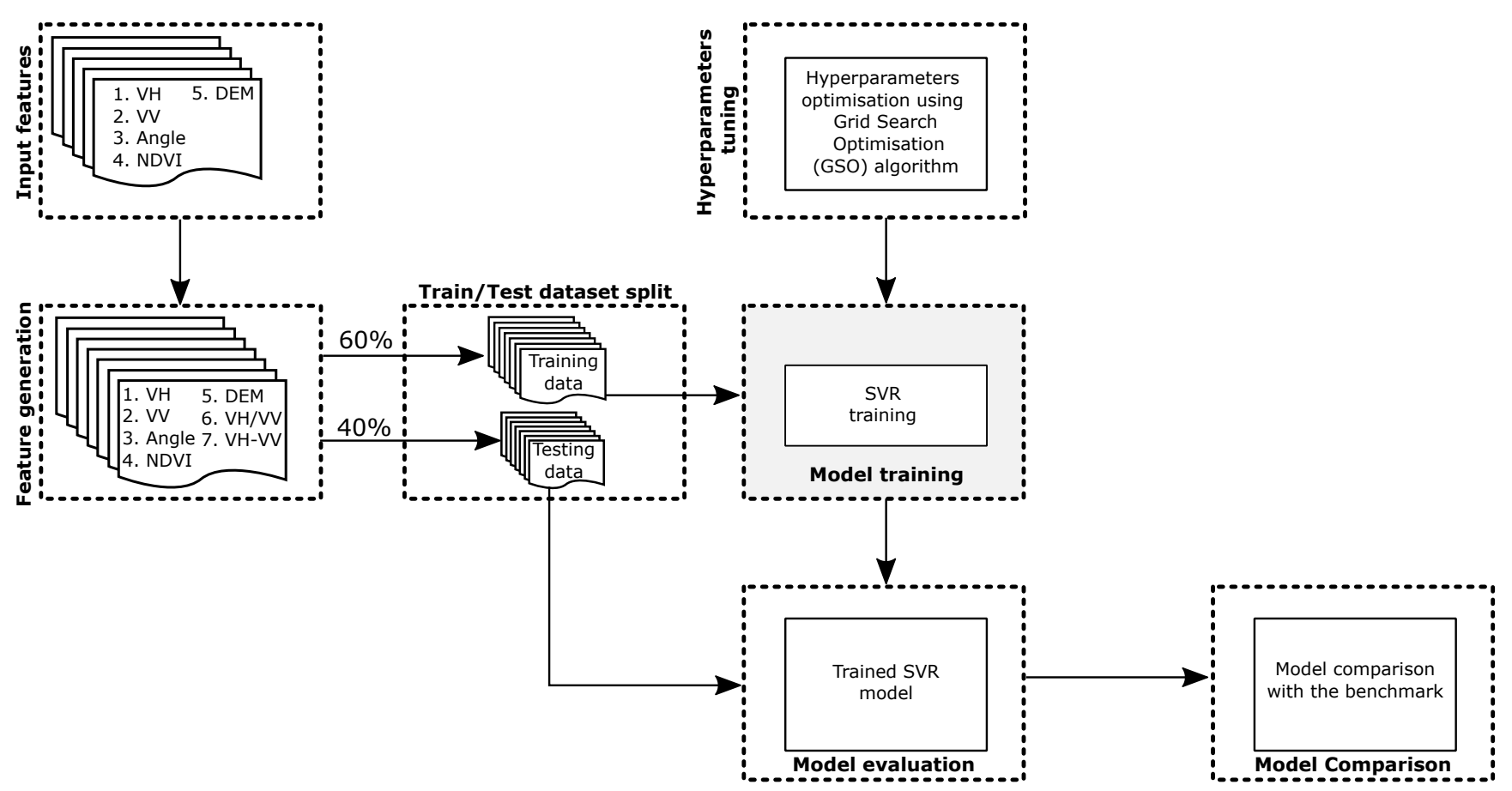

Figure 6. Flowchart illustrates the overall methodology used to set-up the SVR model.

We applied the Principal Component Analysis (PCA) to select the most uncorrelated information from the feature data. We selected the first five principal components of the feature data. This explains about $99 \%$ variance and reduces the time and space complexity required for the training and evaluation of the model. We then standardised the features to find the optimal scaling methods to predict surface roughness. We applied different methods, i.e., Not Standardised (NS), Center Mean (CM), Z-score Mean (ZM), Min-Max $(\mathrm{MM})$, and Scale (S), to standardise our input features. Table 2 reports the description of different standardisation methods.

Finally, we use the result of each standardisation method (i.e., PCA-NS-SVR, PCA-CMSVR, PCA-ZM-SVR, PCA-MM-SVR, and PCA-S-SVR) to train the SVR model (Figure 7).

Table 2. Different scaling methods and their descriptions.

\begin{tabular}{|c|c|c|}
\hline $\begin{array}{c}\text { Standardisation } \\
\text { Method }\end{array}$ & Formulation & Description \\
\hline Not Standardised & $\mathrm{x}_{\mathrm{s}}=\mathrm{x}$ & Same as input \\
\hline Center Mean & $x_{s}=x-\bar{x}$ & Features are centered with zero mean. \\
\hline Z-score Mean & $\mathrm{x}_{\mathrm{s}}=\frac{\mathrm{x}-\overline{\mathrm{x}}}{\sigma}$ & $\begin{array}{l}\text { It converts the features to a common scale with zero mean and unit } \\
\text { standard deviation. It has same skewness and kurtosis as that of } \\
\text { original data. }\end{array}$ \\
\hline Min-Max & $\mathrm{x}_{\mathrm{s}}=\frac{\mathrm{x}-\mathrm{x}_{\min }}{\mathrm{x}_{\max }-\mathrm{x}_{\min }}$ & $\begin{array}{l}\text { It converts the features to an identical range }[0,1] \text {. The extreme values } \\
\text { has strong influence on the final output. }\end{array}$ \\
\hline Scale & $\mathrm{x}_{\mathrm{s}}=\frac{x}{\sigma}$ & Features are scaled by the standard deviation. \\
\hline
\end{tabular}

Note: $x_{S}$ is the standardised data, $x$ is the original data, $\bar{x}$ is the mean of $x, \sigma$ is the standard deviation of $x, x_{\min }$ is the minimum value of $x$ and $x_{\max }$ is the maximum value of $x$. 


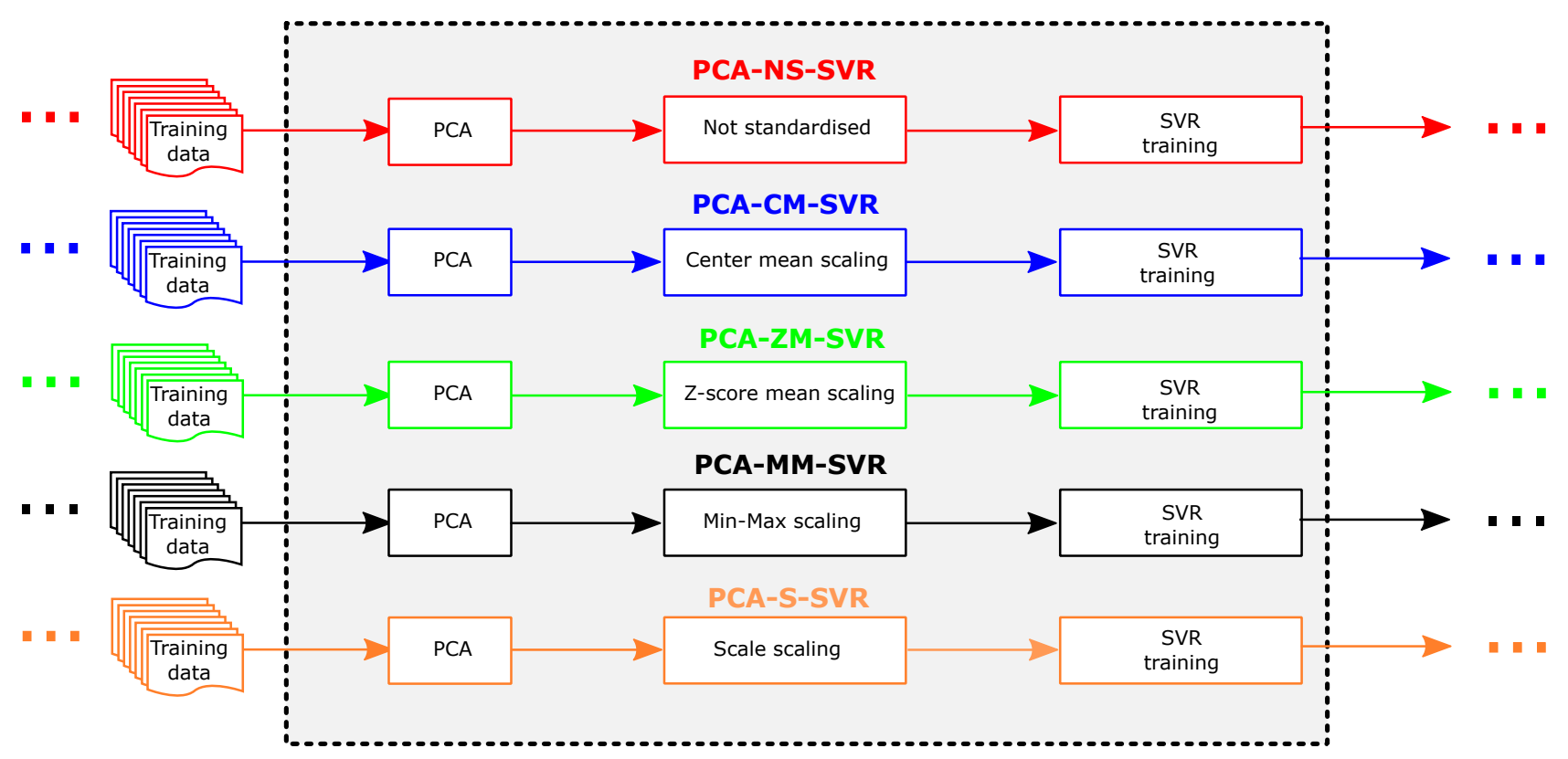

Figure 7. SVR variants based on dimension reduction and scaling.

\subsubsection{Hyperparameter Optimisation}

The hyperparameters ( $\epsilon$ and $C$ ) of the SVR model determine the predictive efficiency and training error in the model. A condition where the overall residual is greater than $\epsilon$, the hyperparameter $C$ penalises the model output. A lower value of $C$ results in computational complexity and a higher value of $C$ in model under-fitting. To overcome these problems, we use the universal grid search algorithm to optimise the hyperparameter $(C)$ by keeping the $\epsilon$ fixed in the SVR model. The Gird search algorithm needs an objective function to estimate the optimal value of the hyperparameter. In a regression model, the MSE is the most commonly used objective function [85]. The objective function (MSE) reads;

$$
\frac{1}{n} \sum_{i=1}^{n}\left(Y_{i}-\widehat{Y}_{i}\right)^{2}
$$

where $n$ is the size of testing samples, $Y_{i}$ is the observed values, $\widehat{Y}_{i}$ is the predicted values. The grid search algorithm minimises the objective function to find the optimal value of $C$. Table 3 reports the optimal values of hyperparameters.

Table 3. Simulation parameters of the SVR model.

\begin{tabular}{lc}
\hline Parameters & Values \\
\hline Penalty factor $(C)$ & $0.1-0.5$ \\
Epsilon $(\epsilon)$ & 0.1 \\
Kernel & Homogeneous Polynomial \\
Polynomial degree $(d)$ & 1 \\
Gamma $(\gamma)$ & 1 \\
\hline
\end{tabular}

\section{Result}

\subsection{Feature Importance}

The bar plot (Figure 8a) shows relative importance of our input features. A feature that has higher relative importance score is considered more important in the model for predicting surface roughness. 


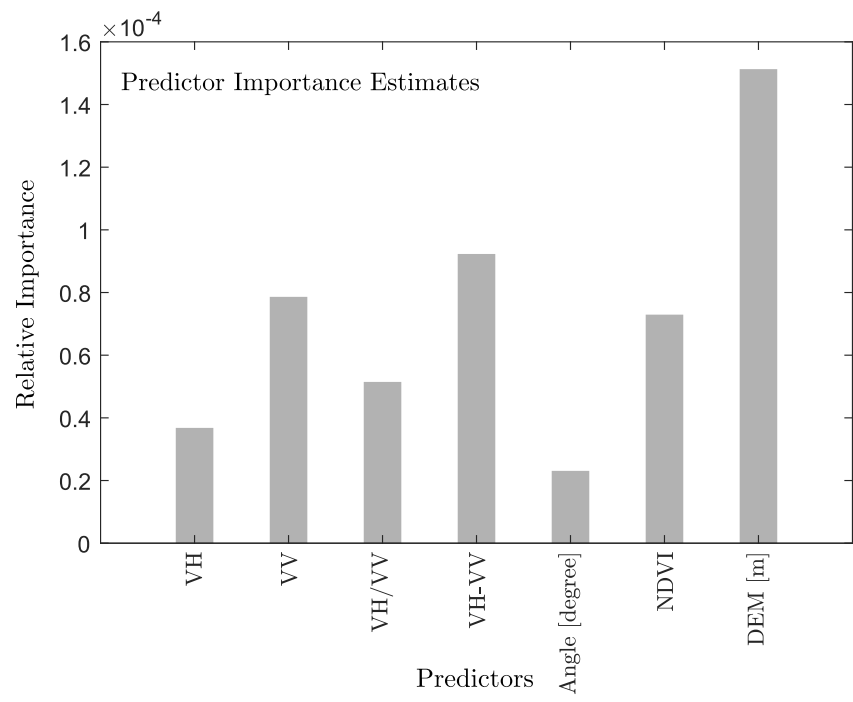

(a)

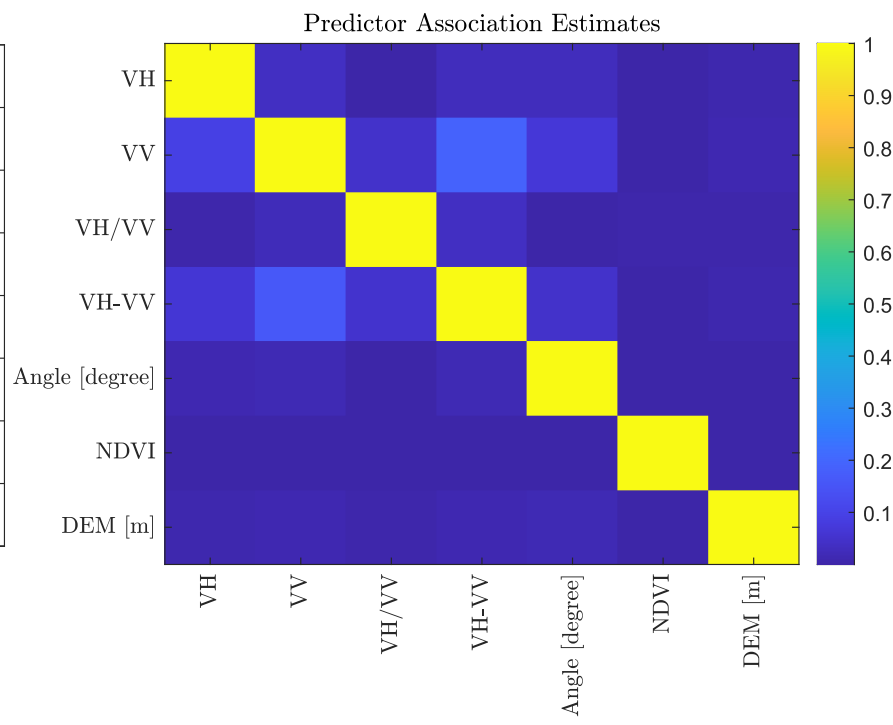

(b)

Figure 8. (a) Bar plot illustrates the relative feature importance score of the input features, (b) feature association matrix.

Among all the input features we used for training SVR models, the incidence angle has the lowest, and DEM has the highest feature importance score. This indicates incidence angle has less impact, and DEM has more impact in predicting the surface soil roughness. Additional features (VH/VV and VH-VV) generated from the linear data fusion have more importance than the native features. It is important to highlight that the feature importance only calculates the relative importance, without the segregation of irrelevant and relevant features [86]. It is a common practice in machine learning to eliminate noisy, redundant, and irrelevant features, as they can reduce the prediction accuracy and increase the computational cost.

We applied the backward elimination to identify the irrelevant features in our model [87-91]. It is an iterative approach that eliminates the least important features and re-calculates the model loss (i.e., MSE) in each iteration. If the model loss for a feature decreases, we consider that feature irrelevant and eliminate it from the computation. This process continues until the model loss is constant. Alternatively, if the model loss increases, that feature is relevant and the process is terminated. As the incidence angle has the least feature importance score, we eliminated it using the backward elimination approach and re-calculated the model loss. We observed that, after the elimination of incidence angle, the model loss increased (MSE $=7.9 \times 10^{-16}$ ). This indicates that the incidence angle is not an irrelevant feature in the prediction of soil roughness. Similarly, the elimination of other features degrades the result. This suggests that all seven features are relevant in predicting surface soil roughness. Among them, DEM is the most important. Figure $8 \mathrm{~b}$ shows the Pearson correlations of the features. All the input features are uncorrelated, which suggests the good reliability of our model.

\subsection{Feature Sensitivity}

Feature importance does not examine if a feature is positively or negatively affecting the models. To evaluate this, we performed a sensitivity analysis of our features when predicting the surface roughness. We generated the Partial Dependence Plot (PDP) [92] of each feature with their corresponding histogram (Figure 9). PDP measures the average marginal effect of all features on the predicted variable. The PDP of DEM shows a high partial dependency for surface roughness (Figure 9). The incidence angle and DEM are positive, whereas the NDVI has a negative effect on the surface roughness. The backscatter values $\left(\sigma_{0}\right)$ for $\mathrm{VV}$ and $\mathrm{VH} / \mathrm{VV}$ have a fluctuating positive, and $\mathrm{VH}-\mathrm{VV}$ has a fluctuating negative effect. We did not observe any clear trend for $\mathrm{VH}$. 


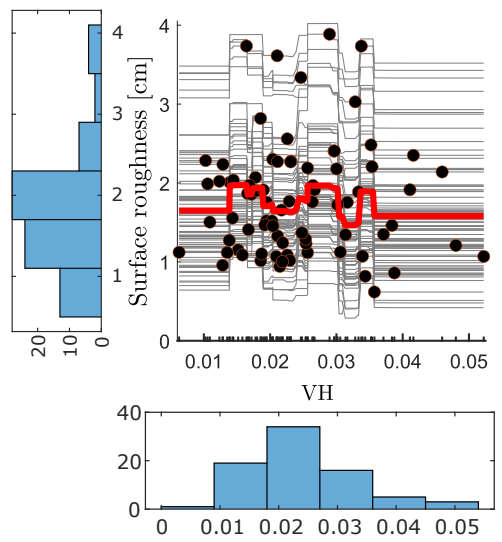

(a)
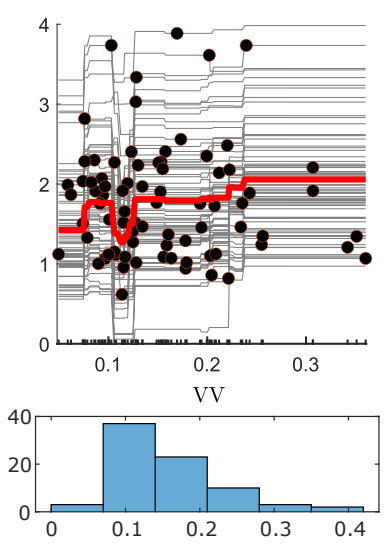

(b)

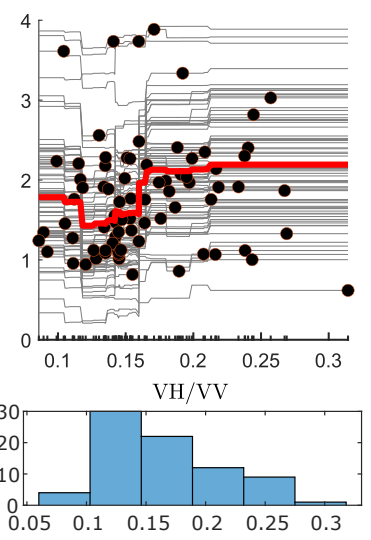

(c)
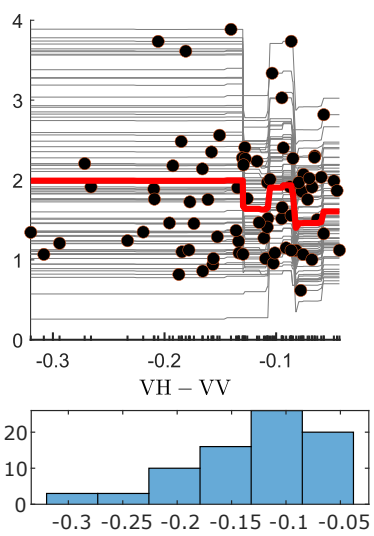

(d)
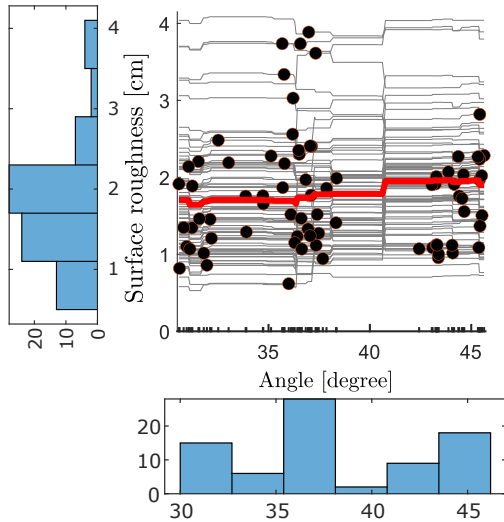

(e)
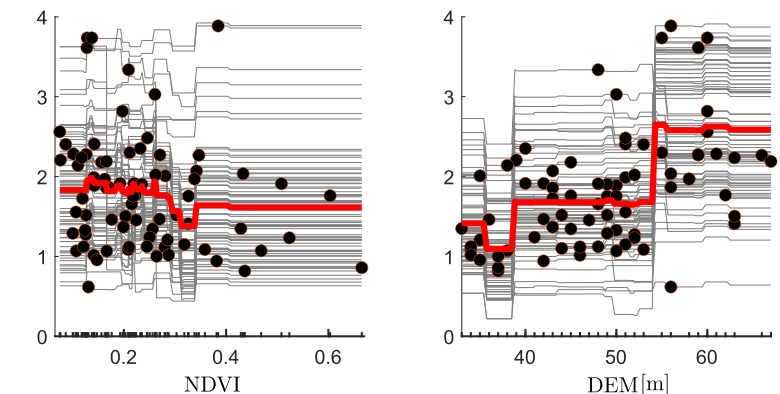

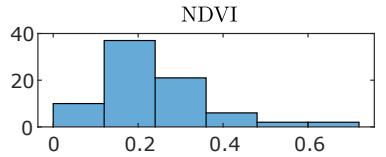

(f)

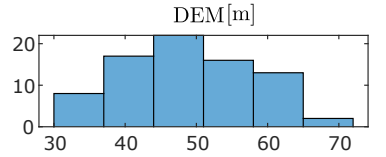

(g)

Figure 9. PDP and ICE plot to show the sensitivity of different input features (i.e.; (a) VH, (b) VV, (c) VH/VV, (d) VH-VV, (e) incidence angle, (f) NDVI, and (g) DEM) on surface roughness. Curves in red and gray illustrate the PDP and ICE respectively. The corresponding histograms illustrate the probability distribution of the individual features and surface roughness.

Furthermore, to explore the localised explanation of individual features at each instance, we plotted the Individual Conditional Expectation (ICE) in the same plot [93]. This is considered a non-linear sensitivity analysis that disaggregates the averaging effects and evaluates the model at each instance. The average of all the ICE lines provides the PDP plot [94-96]. The averaging effect of PDP conceals any heterogeneous relationship present at any particular instance. For example, some instances in the ICE of DEM (between 50 and $55 \mathrm{~m}$ ) behave differently compared to the majority instances (i.e., PDP).

\subsection{Surface Roughness}

We used the different variants of our SVR model to estimate surface roughness and compared the result with the ground measurement. We plot the model surface roughness against the in-situ values (Figure 10). We observed that the PCA-MM-SVR outperforms all other variants of $S V R$, with $R=0.75$ and $R M S E=0.19 \mathrm{~cm}$ (Figure 10). The predicted surface roughness from PCA-MM-SVR accord well with the in-situ values. All the datapoints are clustered around the 1:1 line. The result of PCA-CM-SVR also compares well with the ground measurement. This ranks second-best in predicting the surface roughness with $\mathrm{R}=0.70$ and RMSE $=0.25 \mathrm{~cm}$. The non-standardise version of SVR (PCA-NS-SVR) poorly performs with $\mathrm{R}=0.50$ and $\mathrm{RMSE}=0.44 \mathrm{~cm}$. This is primarily because PCA-NSSVR underestimates the surface roughness value, and the datapoints are non-uniformly distributed on a 1:1 line with large scattering. This indicates bias in the prediction. 




Figure 10. Predicted surface roughness against the in-situ measurement. Symbols in different colours and shape illustrate the different variants of SVR models used for the prediction.

\section{Discussion}

\subsection{Comparison with the Benchmark Machine Learning Models}

Our results show that the PCA-MM-SVR predicts surface soil roughness more accurately compared to the other variants of SVR models. However, any conclusion based solely on a comparison of the different variants of the same machine-learning model may lead to a biased result. To overcome this, we compare the performance of the SVR model with the benchmark machine-learning algorithms (i.e., GPR, GRNN, BDT, Bragging Ensemble Learning, and Boosting Ensemble Learning). Apart from these benchmark algorithms, we also compared the performance of the SVR models with the recently emerged automated machine learning (AutoML) algorithms [97]. An AutoML module is embedded in MATLAB ${ }^{\circledR}$ and can be accessed through fitrauto library. It automatically selects the regression model (i.e., SVR, GPR, linear regression, BDT, and ensemble learning) with optimised hyperparameters. This uses Bayesian optimisation to iteratively tune the model through parallel computing by assuming $\log (1+$ MSE $)$ as an objective function.

In machine learning, it is customary to use R and RMSE values to evaluate the model performance. These metrics are suitable for estimating the accuracy of a single model, but not for comparing the performance of different machine-learning models [98-100]. To ensure a fair evaluation, we use performance metrics such as: Akaike's Information Criterion (AIC), corrected AIC (AICc), and Bayesian Information Criterion (BIC) [101] (Appendix B). These metrics penalise the model for a higher number of model parameters to select the best model $[102,103]$. The model with a lower value of AIC, AICC, and BIC is preferred.

Table 4 reports the performance of other machine learning models, evaluated using the same training and testing datasets. The SVR performs relatively well compared to 
the other machine-learning models. The PCA-MM-SVR exhibits the lowest values of AIC, and BIC amongst all other methods; this indicates the best goodness-of-fit. We also evaluate the model performance in terms of computational time complexity (using CPU @ $3.3 \mathrm{GHz}, 10$ cores). We observed that the computational time complexity of PCA-MM-SVR is optimal. The time complexity of the non-standardised variant of SVR (i.e., PCA-NS-SVR) is relatively high.

Table 4. Comparison of SVR model with the benchmark machine-learning algorithms.

\begin{tabular}{|c|c|c|c|c|c|c|c|}
\hline \multirow{2}{*}{ Methods } & \multicolumn{7}{|c|}{ Parameters } \\
\hline & $\mathbf{R}$ & RMSE (cm) & $\operatorname{MSE}\left(\mathrm{cm}^{2}\right)$ & AIC & $\mathrm{AICc}$ & BIC & Time (s) \\
\hline \multicolumn{8}{|l|}{ SVR } \\
\hline PCA-NS-SVR & 0.50 & 0.44 & 0.19 & -87.01 & -39.42 & -83.39 & 0.95 \\
\hline PCA-CM-SVR & 0.70 & 0.25 & 0.06 & -138.53 & -90.95 & -134.92 & 0.26 \\
\hline PCA-ZM-SVR & 0.67 & 0.22 & 0.05 & -147.12 & -99.53 & -143.51 & 0.12 \\
\hline PCA-MM-SVR & $0.75 *$ & $0.19 *$ & $0.04 *$ & $-160.32 *$ & -112.74 & $-156.71^{*}$ & $0.08^{*}$ \\
\hline PCA-S-SVR & 0.65 & 0.26 & 0.07 & -133.70 & -86.14 & -130.09 & 0.18 \\
\hline \multicolumn{8}{|l|}{ GPR } \\
\hline PCA-NS-GPR & 0.30 & 0.21 & 0.04 & -152.97 & -105.38 & -149.35 & 1.09 \\
\hline PCA-CM-GPR & 0.23 & 0.24 & 0.06 & -139.93 & -92.35 & -136.32 & 0.25 \\
\hline PCA-ZM-GPR & 0.44 & 0.32 & 0.10 & -116.37 & -68.78 & -112.75 & 0.16 \\
\hline PCA-MM-GPR & 0.29 & 0.24 & 0.06 & -140.10 & -92.51 & -136.48 & 0.11 \\
\hline PCA-S-GPR & 0.46 & 0.27 & 0.07 & -131.36 & -83.77 & -127.75 & 0.30 \\
\hline \multicolumn{8}{|l|}{ GRNN } \\
\hline PCA-NS-GRNN & 0.11 & 0.63 & 0.40 & 752.17 & -113.76 & 1483.87 & 1.68 \\
\hline PCA-CM-GRNN & 0.25 & 0.55 & 0.31 & 740.11 & -125.82 & 1471.81 & 0.36 \\
\hline PCA-ZM-GRNN & 0.51 & 0.28 & 0.08 & 680.14 & -185.80 & 1411.84 & 0.23 \\
\hline PCA-MM-GRNN & 0.67 & 0.04 & 0.00 & 509.29 & $-356.65 *$ & 1241.00 & 0.17 \\
\hline PCA-S-GRNN & 0.51 & 0.21 & 0.05 & 653.93 & -212.01 & 1385.63 & 0.45 \\
\hline \multicolumn{8}{|l|}{ BDT } \\
\hline PCA-NS-BDT & 0.22 & 0.54 & 0.29 & -65.80 & -17.80 & -60.38 & 1.09 \\
\hline PCA-CM-BDT & 0.41 & 0.54 & 0.29 & -65.95 & -17.95 & -60.53 & 0.19 \\
\hline PCA-ZM-BDT & 0.36 & 0.55 & 0.30 & -64.95 & -16.95 & -59.53 & 0.10 \\
\hline PCA-MM-BDT & 0.19 & 0.61 & 0.37 & -55.17 & -7.17 & -49.75 & 0.08 \\
\hline PCA-S-BDT & 0.24 & 0.53 & 0.28 & -67.32 & -19.32 & -61.90 & 0.26 \\
\hline \multicolumn{8}{|l|}{$\begin{array}{c}\text { Bagging EL } \\
\text { (Random Forest) }\end{array}$} \\
\hline PCA-NS-BAGG & 0.44 & 0.24 & 0.06 & 55.36 & -263.51 & 245.06 & 3.07 \\
\hline PCA-CM-BAGG & 0.56 & 0.24 & 0.06 & 65.61 & -253.27 & 255.31 & 1.16 \\
\hline PCA-ZM-BAGG & 0.58 & 0.24 & 0.06 & 63.44 & -255.43 & 253.14 & 0.82 \\
\hline PCA-MM-BAGG & 0.50 & 0.22 & 0.05 & 55.36 & -263.51 & 245.06 & 0.71 \\
\hline PCA-S-BAGG & 0.46 & 0.20 & 0.04 & 46.46 & -272.41 & 236.16 & 1.05 \\
\hline
\end{tabular}


Table 4. Cont.

\begin{tabular}{|c|c|c|c|c|c|c|c|}
\hline \multirow{2}{*}{ Methods } & \multicolumn{7}{|c|}{ Parameters } \\
\hline & $\mathbf{R}$ & RMSE (cm) & $\operatorname{MSE}\left(\mathrm{cm}^{2}\right)$ & AIC & AICc & BIC & Time (s) \\
\hline \multicolumn{8}{|l|}{$\begin{array}{l}\text { Boosting EL } \\
\text { (LSBoost) }\end{array}$} \\
\hline PCA-NS-BOOST & 0.31 & 0.69 & 0.47 & 160.17 & -158.70 & 349.87 & 1.48 \\
\hline PCA-CM-BOOST & 0.38 & 0.61 & 0.37 & 148.03 & -170.83 & 337.73 & 0.54 \\
\hline PCA-ZM-BOOST & 0.50 & 0.57 & 0.32 & 142.60 & -176.26 & 332.30 & 0.38 \\
\hline PCA-MM-BOOST & 0.20 & 0.65 & 0.42 & 154.23 & -164.65 & 343.93 & 0.36 \\
\hline PCA-S-BOOST & 0.36 & 0.60 & 0.36 & 146.92 & -171.95 & 336.61 & 0.51 \\
\hline \multicolumn{8}{|l|}{ AutoML } \\
\hline PCA-NS-AutoML & 0.44 & 0.19 & 0.04 & 284.17 & -232.59 & 690.68 & 5.82 \\
\hline PCA-CM-AutoML & 0.59 & 0.21 & 0.04 & 292.12 & -224.64 & 698.62 & 3.98 \\
\hline PCA-ZM-AutoML & 0.59 & 0.20 & 0.04 & 291.05 & -225.70 & 697.55 & 3.87 \\
\hline PCA-MM-AutoML & 0.32 & 0.21 & 0.05 & 337.79 & -220.62 & 784.04 & 3.79 \\
\hline PCA-S-AutoML & 0.38 & 0.20 & 0.04 & 288.57 & -228.18 & 695.07 & 4.32 \\
\hline
\end{tabular}

Note: The values marked in blue and red represent the best and worst for each column. Values marked in asterisk represent the global best.

Other than SVR, the GRNN performs well and ranks second in terms of performance evaluation. In GRNN, the mix-max scaling variant (i.e., PCA-MM-GRNN) performs better $(\mathrm{R}=0.67, \mathrm{RMSE}=0.04 \mathrm{~cm}, \mathrm{AIC}=509.3, \mathrm{AIC} \mathrm{c}=-356.7$, and $\mathrm{BIC}=1241)$. This model is computationally more efficient than its other variants. Among the AutoML variants, we found that PCA-ZM-AutoML ranks third in terms of performance evaluation by outperforming all other variants, with $\mathrm{R}=0.59, \mathrm{RMSE}=0.20 \mathrm{~cm}, \mathrm{AIC}=291.05, \mathrm{AIC}=-225.70$, and $\mathrm{BIC}=784.04$. We observed that the time complexity of mix-max and non-standardised scaling variant behave in a similar way for all the machine-learning models. The performance of mix-max scaling is the best in terms of computational time complexity and relatively low for the non-standardised scaling.

\subsection{Comparison with Backscatter Models}

We also compared the PCA-MM-SVR model's result with the different empirical, semi-empirical backscatter, and regression models. We applied modified Dubois, modified Oh 2002, and modified Oh 2004 models [28-30] to estimate the surface roughness of the Kosi Fan from dual polarised Sentinel-1 images [56,104,105]. We inverted these models to obtain surface roughness from single co-polarised (i.e., VV) and single cross-polarised images (i.e., VH), and in-situ soil moisture. The inversion of different backscatter models is explained in Appendix C. Surface roughness can be estimated from SAR images by using calibrated regression curves. For example, Srivastava et al. [43] have proposed that the empirical coefficients of the linear regression model retrieve surface roughness for the Indian soils from the multi-polarized Envisat-1 ASAR images. We use this regression model to estimate the surface soil roughness of the Kosi Fan.

The surface roughness from backscatter and regression models is subjected to systematic errors and model biases. To obtain a fair comparison between the SVR, backscatter, and regression models, we use un-bias RMSE (ubRMSE) instead of RMSE. Table 5 reports a comparison of modelled surface roughness with the ground measurements. 
Table 5. Comparison of soil moisture estimated from SVR with the result of different backscatter and empirical regression models.

\begin{tabular}{cccccc}
\hline \multirow{2}{*}{ Parameters } & \multicolumn{5}{c}{ Methods } \\
\cline { 2 - 6 } & Modified Dubois & Modified Oh, 2002 & Modified Oh, 2004 & Srivastava, 2008 & PCA-MM-SVR \\
\hline R & 0.34 & 0.08 & 0.07 & 0.11 & 0.75 \\
ubRMSE (cm) & 1.25 & 0.86 & 1.35 & 0.07 & 0.08 \\
MSE $\left(\mathbf{c m}^{\mathbf{2}}\right)$ & 0.60 & 0.31 & 1.23 & 0.23 & 0.04 \\
\hline
\end{tabular}

Among all the models discussed above, the PCA-MM-SVR machine learning performs better $\left(\mathrm{R}=0.75\right.$, ubRMSE $=0.08 \mathrm{~cm}$, and MSE $\left.=0.04 \mathrm{~cm}^{2}\right)$. The accuracy of SVR is relatively high compared to the backscatter and regression models. This is probably because the SVR considers a higher number of input features to predict the soil roughness as compared to the backscatter and regression-based models.

\subsection{Surface Roughness of the Kosi Fan}

Finally, we used the PCA-MM-SVR model to predict the surface roughness of the Kosi Fan for two consecutive satellite passes (11-12 and 17-18 December 2019) of the Sentinel-1. Figure 11 shows the spatial and temporal variation in surface roughness and its anomaly on the Kosi Fan Surface. The time difference between the two consecutive passes of Sentinel-1 A and B satellites is six days; we do not expect much change in the surface roughness. This is clearly reflected by the cross-section profiles drawn at a common region of the surface roughness maps of two different dates (Figure 11). We observed the negative surface roughness anomalies where surface roughness values were less than $1.5 \mathrm{~cm}$ and positive anomalies where the surface roughness values were greater than $1.5 \mathrm{~cm}$.

Interestingly, we observed some spatial patterns in the surface roughness of the Kosi Fan. Visually, it appears that the surface roughness is high near the apex of the fan and decreases towards the toe. Based on the elevation variation, we categorised the fan surface into proximal (110-70 m), middle (70-50 m), and distal (50-30 m) part. We drew the surface roughness profile along a longitudinal transect from the apex to the fan toe (Figure 12). We can clearly see that the surface decreases non-linearly (approximated using a nonlinear second-order polynomial equation) along the transect. The histogram of surface roughness in the proximal, middle, and distal parts appears to be normally distributed. We found a mild decrease in the average surface roughness from the proximal $(1.7 \pm 0.5 \mathrm{~cm})$, middle $(1.2 \pm 0.3 \mathrm{~cm})$, to the distal $(0.9 \pm 0.2 \mathrm{~cm})$ part of the Kosi Fan. This is consistent with the values measured in the field. Further, it is important to note, on the Kosi fan, that the elevation (110-30 m) and median grain size (300-100 $\mu \mathrm{m})$ gradually decreases from the proximal to distal part. This indicates a possible control of the grain size of the soil sediments and elevation on the surface roughness.

Further, we observed that the dependency of the surface soil roughness on different features is highly dynamic and unclear. We observed no clear trend between the surface soil roughness and the features (Figure 9). However, an overall trend (or impact) is visible, with few features. For example, we observed a positive impact of DEM and incidence angle with the surface soil roughness. This observations are in consistent with the recent studies $[40,106]$.

\subsection{Sensitivity Analysis}

Finally, we performed a sensitivity analysis of the PCA-MM-SVR machine learning model to assess the impact of individual features on the surface soil roughness. At every iteration, we estimated surface roughness by introducing a small uncertainty $( \pm 5 \%$ and $\pm 10 \%$ ) in any one input feature at a particular time and keeping the remaining features constant. This was carried out for all the input features and the results were compared. We observed that an introduction of $\pm 10 \%$ errors in the input features of the PCA-MM-SVR model resulted in an approximately $\pm 1 \%$ change in the output (Figure 13). 

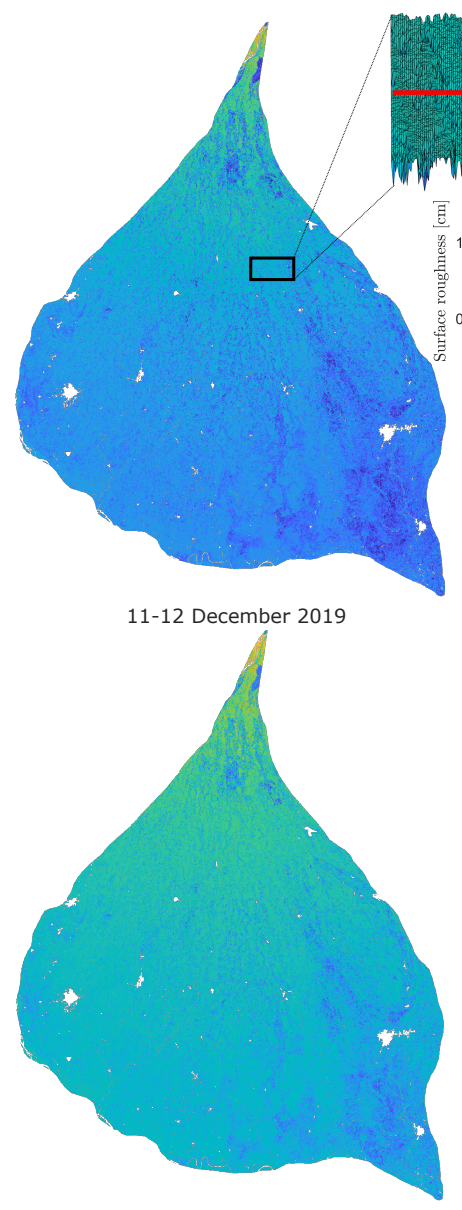

11-12 December 2019
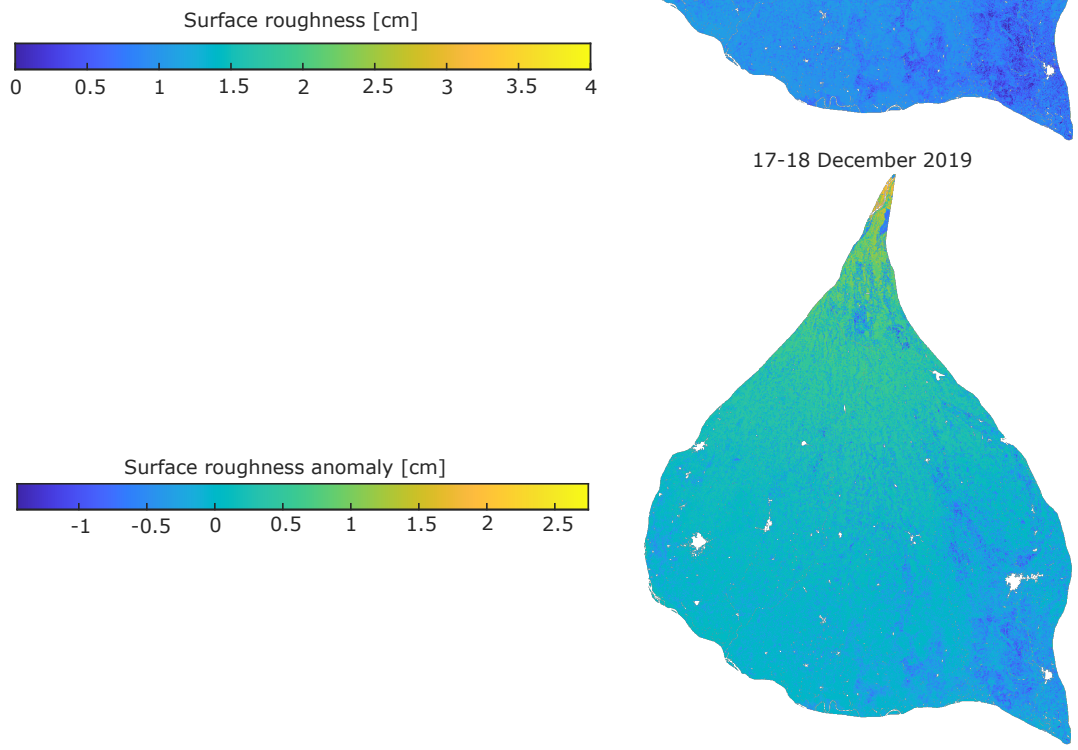

17-18 December 2019

Figure 11. Spatial distribution of surface roughness predicted from PCA-MM-SVR (top) and the corresponding anomaly (bottom). The anomaly is calculated by subtracting the surface roughness at each pixel with the mean surface roughness value of the entire fan. The pixels in white represent invalid regions.
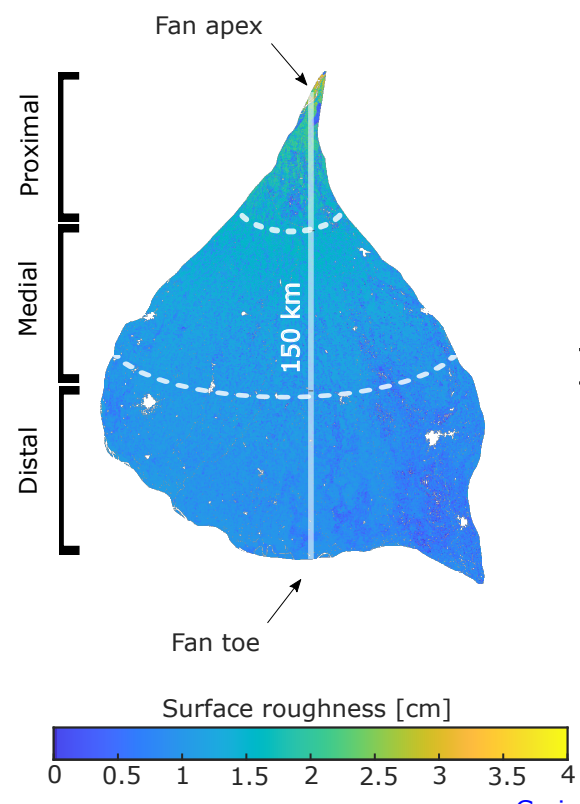
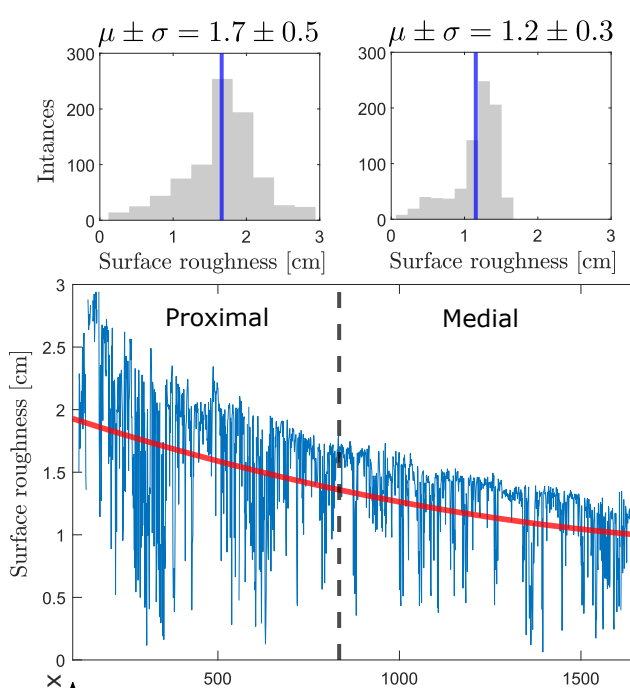

$$
\text { 䒢 }
$$

Surface roughness $[\mathrm{cm}]$



Surface roughness $[\mathrm{cm}]$

Distal

Grain size

$(300-250) \mu \mathrm{m}$

Figure 12. Surface roughness variation from the proximal to distal part of the Kosi fan. The graph in the bottom right illustrates the surface roughness against the distance from fan apex to the toe. Histograms show the corresponding distribution of surface roughness in the proximal, middle and distal parts of the Kosi Fan. 


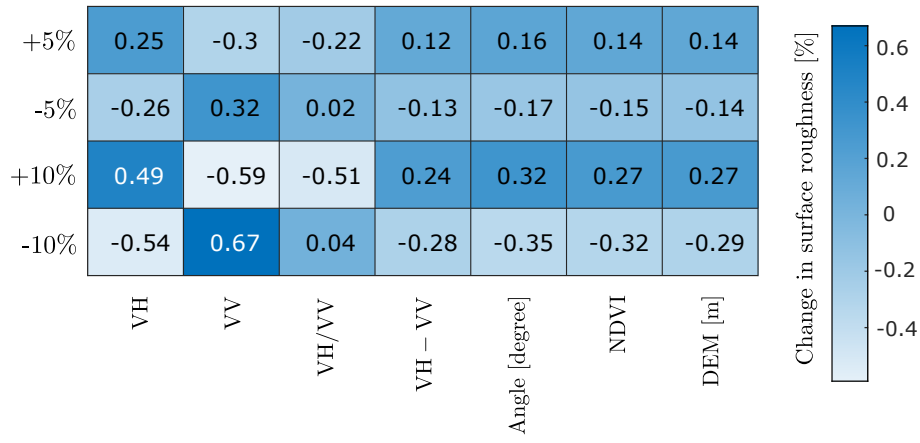

Figure 13. Heat map illustrates the the sensitivity of the PCA-MM-SVR model for $+5 \%,-5 \%,+10 \%$, and $-10 \%$ uncertainty in the input features.

\section{Conclusions}

We compared the accuracy of surface roughness estimated from SVR models with six different benchmark machine-learning algorithms (i.e., GPR, GRNN, BDT, BAGG, BOOST, and AutoML) and three backscatter models (modified Dubois, modified Oh 2002, and modified Oh 2004). We conclude that the PCA-MM-SVR model outperforms all the different variants of SVR, different benchmark machine learning, backscatter, and empirical regression models in terms of accuracy and computational time complexity. The PCA-MMSVR model is relatively more sensitive to uncertainly in the VV polarisation as compared to the other input features. On the Kosi Fan, the surface roughness appears to be more in the proximal and decreases gradually towards the distal part of the fan. Although it is not clear at this stage, we suspect that this could be associated with the elevation (110-30 m) and median grain size variation (300-100 $\mu \mathrm{m})$ from proximal to the distal part of the fan.

This study provides a robust approach to estimate surface soil roughness from optical and SAR remote-sensing data. A comprehensive work using multiple SAR sensor data fusion may be examined in the future to assess the prediction of surface roughness using different machine-learning models. The result of this study can be used in various applications, such as: to study soil erosion, surface soil moisture, infiltration, overland flow, sediment detachment, and many other applications in earth sciences.

Author Contributions: A.S.: Conceptualization, Methodology, Software, Validation, Formal analysis, Writing-Original Draft Preparation, Visualization. K.G.: Conceptualization, Methodology, Software, Validation, Formal Analysis, Writing-Original Draft, Visualization, Supervision, Funding Acquisition. A.K.R. and Z.B. have contributed in the data collection in the field. All authors have read and agreed to the published version of the manuscript.

Funding: This research was funded by the Space Applications Centre (SAC-ISRO) under the NASAISRO Synthetic Aperture Radar (NISAR) mission through grant Hyd-01.

Institutional Review Board Statement: Not applicable.

Informed Consent Statement: Not applicable.

Data Availability Statement: All the satellite images used in this study are publicly available. We have provided the in-situ measurements in Table A1. The algorithms used in this study can be made available upon a reasonable request to the corresponding and first author.

Acknowledgments: We acknowledge IISER Bhopal for providing institutional supports. We are thankful to the Space Applications Centre, Ahmadabad (SAC-ISRO) for providing research grant (grant no: Hyd-01) under the NASA-ISRO Synthetic Aperture Radar (NISAR) mission. Abhilash Singh would like to acknowledge the Department of Science and Technology (DST), Government of India for providing funding to pursue PhD through the DST-INSPIRE fellowship (grant no. DST/INSPIRE Fellowship/IF180001) scheme. We would also like to acknowledge Gaurav Kailash Sonkar and Jitendra Kumar for their extended support during the field work. We are thankful to the editor and all the four anonymous reviewers for their comments and suggestions.

Conflicts of Interest: The authors declare no conflict of interest. 


\section{Appendix A}

Surface roughness measurements on the Kosi Fan (Table A1).

Table A1. Details of the ground condition and surface roughness measured in the field.

\begin{tabular}{|c|c|c|c|c|c|c|c|c|c|c|}
\hline Site ID & Longitude & Latitude & $\begin{array}{c}\text { Date } \\
\text { (dd-mm-yyyy) }\end{array}$ & $\begin{array}{c}\text { Mission } \\
\text { Identifier }\end{array}$ & $\begin{array}{l}\text { Surface Roughness } \\
\text { (cm) }\end{array}$ & Lobe & Direction & $\begin{array}{c}\text { Soil Temperature } \\
\left({ }^{\circ} \mathrm{C}\right)\end{array}$ & Landuse & $\begin{array}{c}\text { Training/ } \\
\text { Testing } \\
\end{array}$ \\
\hline 01 & 86.63923 & 26.13257 & 11 December 2019 & S1A & 2.4029 & I & NE & 21 & Uncultivated bare land (Ploughed) & Training \\
\hline 02 & 86.64361 & 26.10979 & 11 December 2019 & S1A & 1.2736 & I & NE & 22 & Uncultivated bare land (Harrowed) & Training \\
\hline 03 & 86.62364 & 26.09691 & 11 December 2019 & S1A & 2.4072 & I & SW & 20 & Uncultivated bare land (Ploughed) & Training \\
\hline 04 & 86.62604 & 26.0954 & 11 December 2019 & $\mathrm{~S} 1 \mathrm{~A}$ & 1.5181 & I & NE & 16 & Uncultivated bare land (Harrowed) & Training \\
\hline 05 & 86.62061 & 26.0632 & 11 December 2019 & $\mathrm{~S} 1 \mathrm{~A}$ & 3.0288 & I & NE & 16 & Uncultivated bare land (Ploughed) & Training \\
\hline 06 & 86.566 & 26.0243 & 11 December 2019 & $\mathrm{~S} 1 \mathrm{~A}$ & 1.5175 & $\mathrm{I}$ & $\mathrm{NE}$ & 18 & Uncultivated bare land (Harrowed) & Training \\
\hline 07 & 86.57533 & 25.97547 & 11 December 2019 & S1A & 1.1172 & I & NE & 19 & Uncultivated bare land (Harrowed) & Training \\
\hline 08 & 86.64431 & 25.99772 & 11 December 2019 & S1A & 1.9886 & I & NE & 23 & Harrowed + wheat sowed & Training \\
\hline 09 & 86.64072 & 26.03379 & 11 December 2019 & S1A & 1.3282 & I & SW & 24 & Uncultivated bare land (Harrowed) & Training \\
\hline 10 & 86.62675 & 26.15357 & 11 December 2019 & S1A & 3.7350 & I & SW & 17 & Furrow field & Training \\
\hline 11 & 86.66584 & 26.19629 & 11 December 2019 & S1A & 3.8858 & I & $\mathrm{NE}$ & 19 & Furrow field & Training \\
\hline 13 & 86.73994 & 26.22444 & 11 December 2019 & S1A & 1.7677 & I & $\mathrm{NE}$ & 20 & Harrowed + wheat sowed & Training \\
\hline 14 & 86.75186 & 26.23693 & 11 December 2019 & S1A & 1.8670 & I & NE & 21 & Uncultivated bare land (Harrowed) & Training \\
\hline 15 & 86.78488 & 26.24503 & 11 December 2019 & S1A & 2.2774 & I & NE & 19 & Uncultivated bare land (Ploughed) & Training \\
\hline 16 & 86.79723 & 26.26185 & 11 December 2019 & S1A & 2.5599 & I & SW & 20 & Uncultivated bare land (Ploughed) & Training \\
\hline 17 & 86.80273 & 26.2389 & 11 December 2019 & S1A & 1.4094 & I & NE & 21 & Uncultivated bare land (Harrowed) & Training \\
\hline 18 & 86.79795 & 26.20753 & 11 December 2019 & S1A & 3.6128 & I & SW & 20 & Furrow field & Training \\
\hline 19 & 86.79031 & 26.18241 & 11 December 2019 & S1A & 3.7361 & I & NE & 20 & Furrow field & Training \\
\hline 20 & 86.76803 & 26.1514 & 11 December 2019 & S1A & 2.3002 & I & NE & 20 & Uncultivated bare land (Ploughed) & Training \\
\hline 21 & 86.65507 & 26.11443 & 11 December 2019 & $\mathrm{~S} 1 \mathrm{~A}$ & 1.2325 & I & $\mathrm{NE}$ & 18 & Harrowed + wheat sowed & Training \\
\hline 22 & 86.70612 & 26.06255 & 11 December 2019 & S1A & 1.1504 & I & NE & 21 & Harrowed + wheat sowed & Training \\
\hline 23 & 86.73248 & 26.04625 & 11 December 2019 & S1A & 0.6181 & I & NE & 21 & Direct stubble seeding & Training \\
\hline 24 & 86.71229 & 26.03606 & 11 December 2019 & S1A & 1.0680 & I & NE & 20 & Uncultivated bare land (Harrowed) & Training \\
\hline 25 & 86.75741 & 26.02952 & 11 December 2019 & S1A & 3.3369 & I & NE & 20 & Uncultivated bare land (Ploughed) & Training \\
\hline 28 & 86.68053 & 25.82926 & 15 December 2019 & S1A & 1.1016 & I & $\mathrm{SE}$ & 18 & Uncultivated bare land (Harrowed) & Training \\
\hline 29 & 86.68639 & 25.78836 & 15 December 2019 & S1A & 1.9144 & I & NW & 18 & Uncultivated bare land (Harrowed) & Training \\
\hline 30 & 86.6876 & 25.74611 & 15 December 2019 & S1A & 1.3448 & II & NW & 19 & Harrowed + maize sowed & Training \\
\hline 31 & 86.71125 & 25.6878 & 15 December 2019 & S1A & 1.0688 & II & NW & 18 & Uncultivated bare land (Harrowed) & Training \\
\hline 32 & 86.69384 & 25.70237 & 15 December 2019 & S1A & 2.2058 & I & NW & 21 & Ploughed + wheat sowed & Training \\
\hline 33 & 86.65567 & 25.72331 & 15 December 2019 & S1A & 2.1397 & I & NW & 20 & Uncultivated bare land (Ploughed) & Training \\
\hline 34 & 86.80625 & 25.91648 & 15 December 2019 & S1A & 1.4551 & II & NW & 18 & Harrowed + wheat sowed & Training \\
\hline 35 & 86.93388 & 25.89581 & 15 December 2019 & S1A & 1.8875 & II & NW & 17 & Harrowed + maize sowed & Training \\
\hline 36 & 87.00225 & 25.90533 & 15 December 2019 & S1A & 2.4824 & II & NW & 20 & Uncultivated bare land (Ploughed) & Training \\
\hline 37 & 87.06107 & 25.90827 & 15 December 2019 & S1A & 1.2896 & II & SE & 20 & Uncultivated bare land (Harrowed) & Training \\
\hline 38 & 87.09836 & 25.92137 & 15 December 2019 & S1A & 1.7548 & II & $\mathrm{SE}$ & 22 & Uncultivated bare land (Harrowed) & Training \\
\hline 39 & 87.21534 & 25.88781 & 15 December 2019 & S1A & 1.7604 & II & $\mathrm{SE}$ & 22 & Uncultivated bare land (Harrowed) & Training \\
\hline 40 & 86.6099 & 25.72783 & 17 December 2019 & S1B & 2.3510 & I & NW & 20 & Uncultivated bare land (Ploughed) & Training \\
\hline 41 & 86.57812 & 25.7314 & 17 December 2019 & S1B & 0.9426 & I & NW & 21 & Direct stubble seeding & Training \\
\hline 42 & 86.54615 & 25.77154 & 17 December 2019 & S1B & 1.2406 & I & NW & 20 & Uncultivated bare land (Harrowed) & Training \\
\hline 43 & 86.52457 & 25.80515 & 17 December 2019 & S1B & 1.4675 & I & NW & 20 & Uncultivated bare land (Harrowed) & Training \\
\hline 44 & 86.53774 & 25.85775 & 17 December 2019 & S1B & 2.1787 & I & $\mathrm{SE}$ & 19 & Uncultivated bare land (Ploughed) & Training \\
\hline 45 & 86.56369 & 25.8713 & 17 December 2019 & S1B & 1.8584 & $\mathrm{I}$ & NW & 20 & Uncultivated bare land (Harrowed) & Training \\
\hline
\end{tabular}


Table A1. Cont.

\begin{tabular}{|c|c|c|c|c|c|c|c|c|c|c|}
\hline Site ID & Longitude & Latitude & $\begin{array}{c}\text { Date } \\
\text { (dd-mm-yyyy) }\end{array}$ & $\begin{array}{c}\text { Mission } \\
\text { Identifier }\end{array}$ & $\begin{array}{c}\text { Surface Roughness } \\
(\mathrm{cm})\end{array}$ & Lobe & Direction & $\begin{array}{c}\text { Soil Temperature } \\
\left({ }^{\circ} \mathrm{C}\right)\end{array}$ & Landuse & $\begin{array}{c}\text { Training/ } \\
\text { Testing }\end{array}$ \\
\hline 46 & 87.46254 & 25.72741 & 17 December 2019 & $\mathrm{~S} 1 \mathrm{~B}$ & 0.8180 & III & NE & 17 & Direct stubble seeding & Testing \\
\hline 47 & 87.42014 & 25.6838 & 17 December 2019 & S1B & 0.8593 & III & $\mathrm{NE}$ & 17 & Direct stubble seeding & Testing \\
\hline 48 & 87.39914 & 25.64069 & 17 December 2019 & S1B & 1.2080 & III & SW & 18 & Uncultivated bare land (Harrowed) & Testing \\
\hline 49 & 87.39871 & 25.60628 & 17 December 2019 & $\mathrm{~S} 1 \mathrm{~B}$ & 1.4618 & III & $\mathrm{NE}$ & 21 & Uncultivated bare land (Harrowed) & Testing \\
\hline 50 & 87.42513 & 25.61369 & 17 December 2019 & $\mathrm{~S} 1 \mathrm{~B}$ & 1.3488 & III & $\mathrm{NE}$ & 21 & Uncultivated bare land (Harrowed) & Testing \\
\hline 51 & 87.034 & 26.29657 & 17 December 2019 & S1B & 2.1895 & II & $\mathrm{NE}$ & 15 & Uncultivated bare land (Ploughed) & Testing \\
\hline 52 & 87.475 & 25.60035 & 18 December 2019 & S1A & 1.0862 & III & SW & 20 & Uncultivated bare land (Harrowed) & Testing \\
\hline 53 & 87.48171 & 25.59672 & 18 December 2019 & S1A & 1.1235 & III & SW & 22 & Uncultivated bare land (Harrowed) & Testing \\
\hline 54 & 87.55177 & 25.60905 & 18 December 2019 & S1A & 1.0174 & III & SW & 20 & Uncultivated bare land (Harrowed) & Testing \\
\hline 55 & 87.54285 & 25.62759 & 18 December 2019 & S1A & 0.9566 & III & SW & 21 & Direct stubble seeding & Testing \\
\hline 56 & 87.53111 & 25.65317 & 18 December 2019 & S1A & 1.0716 & III & $\mathrm{NE}$ & 22 & Uncultivated bare land (Harrowed) & Testing \\
\hline 58 & 87.51138 & 25.70004 & 18 December 2019 & S1A & 2.0085 & III & SW & 21 & Uncultivated bare land (Ploughed) & Testing \\
\hline 59 & 87.51614 & 25.81319 & 18 December 2019 & S1A & 2.0704 & III & $\mathrm{NE}$ & 17 & Uncultivated bare land (Ploughed) & Testing \\
\hline 60 & 87.52789 & 25.82046 & 18 December 2019 & S1A & 1.9143 & III & SW & 17 & Uncultivated bare land (Harrowed) & Testing \\
\hline 61 & 87.54014 & 25.91021 & 18 December 2019 & S1A & 1.9034 & III & $\mathrm{NE}$ & 18 & Uncultivated bare land (Harrowed) & Testing \\
\hline 62 & 87.51805 & 25.99278 & 18 December 2019 & S1A & 1.9106 & III & SW & 18 & Uncultivated bare land (Harrowed) & Testing \\
\hline 63 & 87.50936 & 26.00962 & 18 December 2019 & S1A & 1.1215 & III & SW & 18 & Uncultivated bare land (Harrowed) & Testing \\
\hline 64 & 87.46062 & 26.12101 & 18 December 2019 & S1A & 1.5554 & III & SW & 19 & Uncultivated bare land (Harrowed) & Testing \\
\hline 65 & 87.29737 & 26.22082 & 18 December 2019 & S1A & 1.9698 & III & SW & 17 & Uncultivated bare land (Harrowed) & Testing \\
\hline 66 & 87.27813 & 26.24172 & 18 December 2019 & S1A & 2.2836 & III & SW & 18 & Uncultivated bare land (Ploughed) & Testing \\
\hline 67 & 87.23487 & 26.27511 & 18 December 2019 & S1A & 2.2357 & III & SW & 19 & Uncultivated bare land (Ploughed) & Testing \\
\hline 68 & 87.2269 & 26.24339 & 18 December 2019 & S1A & 1.5040 & III & SW & 20 & Uncultivated bare land (Harrowed) & Testing \\
\hline 69 & 87.2321 & 26.20331 & 18 December 2019 & S1A & 2.2703 & III & SW & 18 & Uncultivated bare land (Ploughed) & Testing \\
\hline 70 & 87.23437 & 26.17834 & 18 December 2019 & S1A & 2.0355 & III & NE & 19 & Ploughed + wheat sowed & Testing \\
\hline 73 & 87.30746 & 25.93218 & 18 December 2019 & S1A & 1.1182 & III & $\mathrm{NE}$ & 17 & Harrowed + maize sowed & Testing \\
\hline 74 & 87.20622 & 26.326 & 18 December 2019 & S1A & 2.2675 & III & SW & 15 & Uncultivated bare land (Ploughed) & Testing \\
\hline 75 & 87.00787 & 26.17258 & 20 December 2019 & S1A & 2.8180 & II & $\mathrm{NE}$ & 16 & Uncultivated bare land (Ploughed) & Testing \\
\hline 76 & 86.99307 & 26.05495 & 20 December 2019 & S1A & 2.0213 & II & $\mathrm{NE}$ & 17 & Uncultivated bare land (Ploughed) & Testing \\
\hline 77 & 86.97813 & 25.77722 & 20 December 2019 & S1A & 1.7262 & II & SW & 18 & Uncultivated bare land (Harrowed) & Testing \\
\hline 78 & 86.96597 & 25.71033 & 20 December 2019 & S1A & 1.3681 & II & $\mathrm{NE}$ & 18 & Uncultivated bare land (Harrowed) & Testing \\
\hline
\end{tabular}




\section{Appendix B}

The performance metrics are estimated according to;

$$
\begin{gathered}
R=\sqrt{1-\frac{S S E}{S S T}} \\
S S E=\sum\left(y_{o b s}-y_{s a t}\right)^{2} \\
S S T=\sum\left(y_{o b s}-\bar{y}_{o b s}\right)^{2} \\
R M S E=\sqrt{M S E}=\sqrt{\frac{1}{n} \sum\left(y_{s a t}-y_{o b s}\right)^{2}}
\end{gathered}
$$

where, SSE is the sum of squares of errors, SST is the sum of squares of total, $y_{o b s}$ is the observed or in-situ values, and $y_{\text {sat }}$ is the satellite derived or predicted values.

$$
\begin{gathered}
A I C=n_{\text {train }} \cdot \ln \left(\frac{S S E}{n_{\text {train }}}\right)+2 \cdot p \\
B I C=n_{\text {train }} \cdot \ln \left(\frac{S S E}{n_{\text {train }}}\right)+p \cdot \ln \left(n_{\text {train }}\right) \\
A I C c=n_{\text {train }} \cdot \ln \left(\frac{S S E}{n_{\text {train }}}\right)+\frac{\left(n_{\text {train }}+p\right)}{\left(1-\frac{(p+2)}{n_{\text {train }}}\right)}
\end{gathered}
$$

where $n_{\text {train }}$ is the number of training samples and $p$ is the number of parameters that the machine learning model evaluates internally.

\section{Appendix C}

Equation (A8) proposed by Dubois et al. [28] can be inverted according to (Equation (A9)) to estimate surface soil roughness (s).

$$
\begin{gathered}
V V=10^{-2.35} \cdot\left(\frac{\cos ^{3} \theta}{\sin ^{3} \theta}\right) \cdot 10^{0.046 \cdot \epsilon \cdot \tan \theta} \cdot(k \cdot s \cdot \sin \theta)^{1.1} \cdot \lambda^{0.7} \\
s=\frac{1}{k \cdot \operatorname{Sin} \theta}\left\{\frac{V V \cdot \operatorname{Sin}^{3} \theta}{\lambda^{0.7} \cdot 10^{-2.35} \cdot \operatorname{Cos}^{3} \theta \cdot 10^{0.046 \cdot \epsilon \cdot \tan \theta}}\right\}^{0.9090}
\end{gathered}
$$

where $\lambda, \theta, k$, and $\epsilon$ are the wavelength, incidence angle, wave number, and soil permitivity respectively.

Equation (A10) proposed by Oh et al. [29] can be inverted according to (Equation (A11)) to estimate soil surface roughness.

$$
\begin{gathered}
V H=0.11 \cdot m_{v}^{0.7} \cdot(\operatorname{Cos} \theta)^{2.2} \cdot\left[1-e^{0.32(k \cdot s)^{1.8}}\right] \\
s=\frac{\left\{\frac{-1}{0.32} \ln \left[1-\frac{V H}{0.11 \cdot m_{v}^{0.7} \cdot(\cos \theta)^{2.2}}\right]\right\}^{0.555}}{k}
\end{gathered}
$$

where $m_{v}$ is the measured volumetric surface soil moisture (in-situ).

Equation (A12) proposed by Oh [30] can be inverted according to (Equation (A13)) to estimate surface roughness:

$$
q=\frac{V H}{V V}=0.095 \cdot(0.13+\sin 1.5 \theta)^{1.4}\left(1-e^{-1.3(k \cdot)^{0.9}}\right)
$$




$$
s=\frac{\left\{\frac{-1}{1.3} \ln \left[1-\frac{q}{0.095 \cdot(0.13+\sin 1.5 \theta)^{1.4}}\right]\right\}^{1.111}}{k}
$$

Linear regression model proposed by Srivastava et al. [43] can be used to estimate surface soil roughness.

$$
s=A+B \cdot[V H--V V]
$$

where $A$ and $B$ are the empirical constants.

\section{References}

1. McColl, K.A.; Alemohammad, S.H.; Akbar, R.; Konings, A.G.; Yueh, S.; Entekhabi, D. The global distribution and dynamics of surface soil moisture. Nat. Geosci. 2017, 10, 100-104. [CrossRef]

2. Helming, K.; Römkens, M.; Prasad, S. Surface roughness related processes of runoff and soil loss: a flume study. Soil Sci. Soc. Am. J. 1998, 62, 243-250. [CrossRef]

3. Wagner, W.; Blöschl, G.; Pampaloni, P.; Calvet, J.C.; Bizzarri, B.; Wigneron, J.P.; Kerr, Y. Operational readiness of microwave remote sensing of soil moisture for hydrologic applications. Hydrol. Res. 2007, 38, 1-20. [CrossRef]

4. Baghdadi, N.; El Hajj, M.; Choker, M.; Zribi, M.; Bazzi, H.; Vaudour, E.; Gilliot, J.M.; Ebengo, D.M. Potential of Sentinel-1 images for estimating the soil roughness over bare agricultural soils. Water 2018, 10, 131. [CrossRef]

5. Alexakis, D.D.; Mexis, F.D.K.; Vozinaki, A.E.K.; Daliakopoulos, I.N.; Tsanis, I.K. Soil moisture content estimation based on Sentinel-1 and auxiliary earth observation products. A hydrological approach. Sensors 2017, 17, 1455. [CrossRef]

6. Verhoest, N.E.; Lievens, H.; Wagner, W.; Álvarez-Mozos, J.; Moran, M.S.; Mattia, F. On the soil roughness parameterization problem in soil moisture retrieval of bare surfaces from synthetic aperture radar. Sensors 2008, 8, 4213-4248. [CrossRef]

7. Romkens, M.; Wang, J. Effect of tillage on surface roughness. Trans. ASAE 1986, 29, 429-0433. [CrossRef]

8. Govers, G.; Takken, I.; Helming, K. Soil roughness and overland flow. Agronomie 2000, 20, 131-146. [CrossRef]

9. Snapir, B.; Hobbs, S.; Waine, T. Roughness measurements over an agricultural soil surface with Structure from Motion. ISPRS J. Photogramm. Remote Sens. 2014, 96, 210-223. [CrossRef]

10. Turner, R.; Panciera, R.; Tanase, M.A.; Lowell, K.; Hacker, J.M.; Walker, J.P. Estimation of soil surface roughness of agricultural soils using airborne LiDAR. Remote Sens. Environ. 2014, 140, 107-117. [CrossRef]

11. Hamze, M.; Baghdadi, N.; El Hajj, M.M.; Zribi, M.; Bazzi, H.; Cheviron, B.; Faour, G. Integration of L-Band Derived Soil Roughness into a Bare Soil Moisture Retrieval Approach from C-Band SAR Data. Remote Sens. 2021, 13, 2102. [CrossRef]

12. Thomsen, L.; Baartman, J.; Barneveld, R.; Starkloff, T.; Stolte, J. Soil surface roughness: comparing old and new measuring methods and application in a soil erosion model. Soil 2015, 1, 399-410. [CrossRef]

13. Saleh, A. Soil roughness measurement: chain method. J. Soil Water Conserv. 1993, 48, 527-529.

14. Hajnsek, I.; Pottier, E.; Cloude, S.R. Inversion of surface parameters from polarimetric SAR. IEEE Trans. Geosci. Remote. Sens. 2003, 41, 727-744. [CrossRef]

15. Merzouki, A.; McNairn, H.; Pacheco, A. Mapping soil moisture using RADARSAT-2 data and local autocorrelation statistics. IEEE J. Sel. Top. Appl. Earth Obs. Remote Sens. 2011, 4, 128-137. [CrossRef]

16. Le Morvan, A.; Zribi, M.; Baghdadi, N.; Chanzy, A. Soil moisture profile effect on radar signal measurement. Sensors 2008, 8, 256-270. [CrossRef]

17. Zheng, X.; Li, L.; Chen, S.; Jiang, T.; Li, X.; Zhao, K. Temporal evolution characteristics and prediction methods of spatial correlation function shape of rough soil surfaces. Soil Tillage Res. 2019, 195, 104417. [CrossRef]

18. Alijani, Z.; Lindsay, J.; Chabot, M.; Rowlandson, T.; Berg, A. Sensitivity of C-Band SAR Polarimetric Variables to the Directionality of Surface Roughness Parameters. Remote Sens. 2021, 13, 2210. [CrossRef]

19. Gharechelou, S.; Tateishi, R.; A Johnson, B. A Simple Method for the Parameterization of Surface Roughness from Microwave Remote Sensing. Remote Sens. 2018, 10, 1711. [CrossRef]

20. Jester, W.; Klik, A. Soil surface roughness measurement-Methods, applicability, and surface representation. Catena 2005, 64, 174-192. [CrossRef]

21. Peng, J.; Albergel, C.; Balenzano, A.; Brocca, L.; Cartus, O.; Cosh, M.H.; Crow, W.T.; Dabrowska-Zielinska, K.; Dadson, S.; Davidson, M.W.; et al. A roadmap for high-resolution satellite soil moisture applications-Confronting product characteristics with user requirements. Remote Sens. Environ. 2020, 252, 112162. [CrossRef]

22. Le Page, M.; Jarlan, L.; El Hajj, M.M.; Zribi, M.; Baghdadi, N.; Boone, A. Potential for the detection of irrigation events on maize plots using sentinel-1 soil moisture products. Remote Sens. 2020, 12, 1621. [CrossRef]

23. Fersch, B.; Jagdhuber, T.; Schrön, M.; Völksch, I.; Jäger, M. Synergies for soil moisture retrieval across scales from airborne polarimetric SAR, cosmic ray neutron roving, and an in situ sensor network. Water Resour. Res. 2018, 54, 9364-9383. [CrossRef]

24. Marzahn, P.; Rieke-Zapp, D.; Ludwig, R. Assessment of soil surface roughness statistics for microwave remote sensing applications using a simple photogrammetric acquisition system. ISPRS J. Photogramm. Remote Sens. 2012, 72, 80-89. [CrossRef]

25. Panciera, R.; Walker, J.P.; Merlin, O. Improved understanding of soil surface roughness parameterization for L-band passive microwave soil moisture retrieval. IEEE Geosci. Remote Sens. Lett. 2009, 6, 625-629. [CrossRef] 
26. Oh, Y.; Sarabandi, K.; Ulaby, F.T. An empirical model and an inversion technique for radar scattering from bare soil surfaces. IEEE Trans. Geosci. Remote Sens. 1992, 30, 370-381. [CrossRef]

27. Oh, Y.; Sarabandi, K.; Ulaby, F.T. An inversion algorithm for retrieving soil moisture and surface roughness from polarimetric radar observation. In Proceedings of the IGARSS'94-1994 IEEE International Geoscience and Remote Sensing Symposium, Pasadena, CA, USA, 8-12 August 1994; Volume 3, pp. 1582-1584.

28. Dubois, P.C.; Van Zyl, J.; Engman, T. Measuring soil moisture with imaging radars. IEEE Trans. Geosci. Remote Sens. 1995, 33, 915-926. [CrossRef]

29. Oh, Y.; Sarabandi, K.; Ulaby, F.T. Semi-empirical model of the ensemble-averaged differential Mueller matrix for microwave backscattering from bare soil surfaces. IEEE Trans. Geosci. Remote Sens. 2002, 40, 1348-1355. [CrossRef]

30. Oh, Y. Quantitative retrieval of soil moisture content and surface roughness from multipolarized radar observations of bare soil surfaces. IEEE Trans. Geosci. Remote Sens. 2004, 42, 596-601. [CrossRef]

31. Attema, E.; Ulaby, F.T. Vegetation modeled as a water cloud. Radio Sci. 1978, 13, 357-364. [CrossRef]

32. Fung, A.K.; Li, Z.; Chen, K.S. Backscattering from a randomly rough dielectric surface. IEEE Trans. Geosci. Remote Sens. 1992, 30, 356-369. [CrossRef]

33. Fung, A.K. Microwave Scattering and Emission Models and Their Applications; Artech House: Norwood, MA, USA, 1994.

34. Shi, J.; Wang, J.; Hsu, A.; O’Neili, P.; Engman, E.T. Estimation of soil moisture and surface roughness parameters using L-band SAR measurements. In Proceedings of the 1995 International Geoscience and Remote Sensing Symposium, IGARSS'95. Quantitative Remote Sensing for Science and Applications, Firenze, Italy, 10-14 July 1995; Volume 1, pp. 507-509.

35. Shi, J.; Wang, J.; Hsu, A.Y.; O'Neill, P.E.; Engman, E.T. Estimation of bare surface soil moisture and surface roughness parameter using L-band SAR image data. IEEE Trans. Geosci. Remote Sens. 1997, 35, 1254-1266.

36. Baghdadi, N.; King, C.; Bourguignon, A.; Remond, A. Potential of ERS and RADARSAT data for surface roughness monitoring over bare agricultural fields: Application to catchments in Northern France. Int. J. Remote Sens. 2002, 23, 3427-3442. [CrossRef]

37. Zribi, M.; Baghdadi, N.; Guérin, C. Analysis of surface roughness heterogeneity and scattering behavior for radar measurements. IEEE Trans. Geosci. Remote Sens. 2006, 44, 2438-2444. [CrossRef]

38. Rahman, M.; Moran, M.; Thoma, D.; Bryant, R.; Collins, C.H.; Jackson, T.; Orr, B.; Tischler, M. Mapping surface roughness and soil moisture using multi-angle radar imagery without ancillary data. Remote Sens. Environ. 2008, 112, 391-402. [CrossRef]

39. Baghdadi, N.; Cresson, R.; Hajj, M.E.; Ludwig, R.; Jeunesse, I.L. Estimation of soil parameters over bare agriculture areas from C-band polarimetric SAR data using neural networks. Hydrol. Earth Syst. Sci. 2012, 16, 1607-1621. [CrossRef]

40. Sawada, Y.; Koike, T.; Aida, K.; Toride, K.; Walker, J.P. Fusing microwave and optical satellite observations to simultaneously retrieve surface soil moisture, vegetation water content, and surface soil roughness. IEEE Trans. Geosci. Remote Sens. 2017, 55, 6195-6206. [CrossRef]

41. Mirmazloumi, S.M.; Sahebi, M.R.; Amani, M. New empirical backscattering models for estimating bare soil surface parameters. Int. J. Remote Sens. 2021, 42, 1928-1947. [CrossRef]

42. Zribi, M.; Dechambre, M. A new empirical model to retrieve soil moisture and roughness from C-band radar data. Remote Sens. Environ. 2003, 84, 42-52. [CrossRef]

43. Srivastava, H.; Patel, P.; Navalgund, R.; Sharma, Y. Retrieval of surface roughness using multi-polarized Envisat-1 ASAR data. Geocarto Int. 2008, 23, 67-77. [CrossRef]

44. Ullmann, T.; Stauch, G. Surface Roughness Estimation in the Orog Nuur Basin (Southern Mongolia) Using Sentinel-1 SAR Time Series and Ground-Based Photogrammetry. Remote Sens. 2020, 12, 3200. [CrossRef]

45. Azizi, A.; Abbaspour-Gilandeh, Y.; Mesri-Gundoshmian, T.; Farooque, A.A.; Afzaal, H. Estimation of soil surface roughness using stereo vision approach. Sensors 2021, 21, 4386. [CrossRef]

46. Hsieh, C.Y.; Fung, A.K.; Nesti, G.; Sieber, A.J.; Coppo, P. A further study of the IEM surface scattering model. IEEE Trans. Geosci. Remote Sens. 1997, 35, 901-909. [CrossRef]

47. Mancini, M.; Hoeben, R.; Troch, P.A. Multifrequency radar observations of bare surface soil moisture content: A laboratory experiment. Water Resour. Res. 1999, 35, 1827-1838. [CrossRef]

48. Wells, N.A.; Dorr, J.A., Jr. Shifting of the Kosi river, northern India. Geology 1987, 15, 204-207. [CrossRef]

49. Sinha, R. The great avulsion of Kosi on 18 August 2008. Curr. Sci. 2009, 97, 429-433.

50. Sinha, R. The Kosi Megafan: The best-known Himalayan megafan. In Landscapes and Landforms of India; Springer: Dordrecht, The Netherlands, 2014; pp. 151-156.

51. Gaurav, K.; Métivier, F.; Devauchelle, O.; Sinha, R.; Chauvet, H.; Houssais, M.; Bouquerel, H. Morphology of the Kosi megafan channels. Earth Surface Dyn. 2015, 3, 321-331. [CrossRef]

52. Gaurav, K.; Tandon, S.; Devauchelle, O.; Sinha, R.; Métivier, F. A single width—Discharge regime relationship for individual threads of braided and meandering rivers from the Himalayan Foreland. Geomorphology 2017, 295, 126-133. [CrossRef]

53. NRSC. District and Category Wise Distribution of Land Use and Land Cover in Bihar (2015-2016); ISRO, 2017. Available online: https:/ / bhuvan.nrsc.gov.in/home/index.php (accessed on 25 March 2021).

54. Singh, A.; Meena, G.K.; Kumar, S.; Gaurav, K. Analysis of the effect of incidence angle and moisture content on the penetration depth of L- and S-band SAR signals into the ground surface. ISPRS Ann. Photogramm. Remote Sens. Spat. Inf. Sci. 2018, 4, 197-202. [CrossRef] 
55. Singh, A.; Meena, G.K.; Kumar, S.; Gaurav, K. Evaluation of the Penetration Depth of L-and S-Band (NISAR mission) Microwave SAR Signals into Ground. In Proceedings of the 2019 URSI Asia-Pacific Radio Science Conference (AP-RASC), New Delhi, India, 9-15 March 2019; p. 1. [CrossRef]

56. Singh, A.; Gaurav, K.; Meena, G.K.; Kumar, S. Estimation of soil moisture applying modified dubois model to Sentinel-1; a regional study from central India. Remote Sens. 2020, 12, 2266. [CrossRef]

57. DeVries, B.; Huang, C.; Armston, J.; Huang, W.; Jones, J.W.; Lang, M.W. Rapid and robust monitoring of flood events using Sentinel-1 and Landsat data on the Google Earth Engine. Remote Sens. Environ. 2020, 240, 111664. [CrossRef]

58. Martins, V.S.; Barbosa, C.C.F.; De Carvalho, L.A.S.; Jorge, D.S.F.; Lobo, F.d.L.; Novo, E.M.L.d.M. Assessment of atmospheric correction methods for Sentinel-2 MSI images applied to Amazon floodplain lakes. Remote Sens. 2017, 9, 322. [CrossRef]

59. Li, J.; Roy, D.P. A global analysis of Sentinel-2A, Sentinel-2B and Landsat-8 data revisit intervals and implications for terrestrial monitoring. Remote Sens. 2017, 9, 902. [CrossRef]

60. Jensen, J.R. Introductory Digital Image Processing: A Remote Sensing Perspective; 2nd ed.; Prentice-Hall Inc.: Hoboken, NJ, USA, 1996.

61. Werner, M. Shuttle radar topography mission (SRTM) mission overview. Frequenz 2001, 55, 75-79. [CrossRef]

62. Farr, T.G.; Kobrick, M. Shuttle Radar Topography Mission produces a wealth of data. Eos Trans. Am. Geophys. Union 2000, 81, 583-585. [CrossRef]

63. Farr, T.G.; Rosen, P.A.; Caro, E.; Crippen, R.; Duren, R.; Hensley, S.; Kobrick, M.; Paller, M.; Rodriguez, E.; Roth, L.; et al. The shuttle radar topography mission. Rev. Geophys. 2007, 45. [CrossRef]

64. Ryan, J.; Hubbard, A.; Irvine-Fynn, T.D.; Doyle, S.H.; Cook, J.; Stibal, M.; Box, J. How robust are in situ observations for validating satellite-derived albedo over the dark zone of the Greenland Ice Sheet? Geophys. Res. Lett. 2017, 44, 6218-6225. [CrossRef]

65. Thakur, K.K.; Vanderstichel, R.; Barrell, J.; Stryhn, H.; Patanasatienkul, T.; Revie, C.W. Comparison of remotely-sensed sea surface temperature and salinity products with in situ measurements from British Columbia, Canada. Front. Mar. Sci. 2018, 5, 121. [CrossRef]

66. Rudin, C. Stop explaining black box machine learning models for high stakes decisions and use interpretable models instead. Nat. Mach. Intell. 2019, 1, 206-215. [CrossRef]

67. Murdoch, W.J.; Singh, C.; Kumbier, K.; Abbasi-Asl, R.; Yu, B. Definitions, methods, and applications in interpretable machine learning. Proc. Natl. Acad. Sci. USA 2019, 116, 22071-22080. [CrossRef]

68. Mountrakis, G.; Im, J.; Ogole, C. Support vector machines in remote sensing: A review. ISPRS J. Photogramm. Remote Sens. 2011, 66, 247-259. [CrossRef]

69. Yu, P.S.; Chen, S.T.; Chang, I.F. Support vector regression for real-time flood stage forecasting. J. Hydrol. 2006, 328, 704-716. [CrossRef]

70. Xiao, X.; Zhang, T.; Zhong, X.; Shao, W.; Li, X. Support vector regression snow-depth retrieval algorithm using passive microwave remote sensing data. Remote Sens. Environ. 2018, 210, 48-64. [CrossRef]

71. Kuter, S. Completing the machine learning saga in fractional snow cover estimation from MODIS Terra reflectance data: Random forests versus support vector regression. Remote Sens. Environ. 2021, 255, 112294. [CrossRef]

72. Ge, J.; Meng, B.; Liang, T.; Feng, Q.; Gao, J.; Yang, S.; Huang, X.; Xie, H. Modeling alpine grassland cover based on MODIS data and support vector machine regression in the headwater region of the Huanghe River, China. Remote Sens. Environ. 2018, 218, 162-173. [CrossRef]

73. Xie, X.; Liu, W.T.; Tang, B. Spacebased estimation of moisture transport in marine atmosphere using support vector regression. Remote Sens. Environ. 2008, 112, 1846-1855. [CrossRef]

74. Okujeni, A.; van der Linden, S.; Tits, L.; Somers, B.; Hostert, P. Support vector regression and synthetically mixed training data for quantifying urban land cover. Remote Sens. Environ. 2013, 137, 184-197. [CrossRef]

75. Su, H.; Wu, X.; Yan, X.H.; Kidwell, A. Estimation of subsurface temperature anomaly in the Indian Ocean during recent global surface warming hiatus from satellite measurements: A support vector machine approach. Remote Sens. Environ. 2015, 160, 63-71. [CrossRef]

76. Malik, A.; Tikhamarine, Y.; Souag-Gamane, D.; Rai, P.; Sammen, S.S.; Kisi, O. Support vector regression integrated with novel meta-heuristic algorithms for meteorological drought prediction. Meteorol. Atmos. Phys. 2021, 133, 891-909. [CrossRef]

77. Jebadurai, J.; Peter, J.D. SK-SVR: Sigmoid kernel support vector regression based in-scale single image super-resolution. Pattern Recognit. Lett. 2017, 94, 144-153. [CrossRef]

78. Ni, K.S.; Nguyen, T.Q. Image superresolution using support vector regression. IEEE Trans. Image Process. 2007, 16, 1596-1610. [CrossRef]

79. Peng, Y.; Albuquerque, P.H.M.; de Sá, J.M.C.; Padula, A.J.A.; Montenegro, M.R. The best of two worlds: Forecasting high frequency volatility for cryptocurrencies and traditional currencies with Support Vector Regression. Expert Syst. Appl. 2018, 97, 177-192. [CrossRef]

80. Ghanem, K.; Aparicio-Navarro, F.J.; Kyriakopoulos, K.G.; Lambotharan, S.; Chambers, J.A. Support vector machine for network intrusion and cyber-attack detection. In Proceedings of the 2017 Sensor Signal Processing for Defence Conference (SSPD), London, UK, 6-7 December 2017; pp. 1-5.

81. Vapnik, V.N. The Nature of Statistical Learning Theory; Springer: New York, NY, USA, 1995. 
82. Drucker, H.; Burges, C.J.; Kaufman, L.; Smola, A.J.; Vapnik, V. Support vector regression machines. In Advances in Neural Information Processing Systems; Denver, CO, USA, December 1997; pp. 155-161. Available online: https://papers.nips.cc/paper/ 1996/ file/d38901788c533e8286cb6400b40b386d-Paper.pdf (accessed on 13 July 2021).

83. Ittner, A.; Schlosser, M. Discovery of Relevant New Features by Generating Non-Linear Decision Trees. In Proceedings of the Second International Conference on Knowledge Discovery and Data Mining, Portland, OR, USA, 2-4 August 1996; pp. 108-113.

84. Toloşi, L.; Lengauer, T. Classification with correlated features: Unreliability of feature ranking and solutions. Bioinformatics 2011, 27, 1986-1994. [CrossRef] [PubMed]

85. Reed, R.; MarksII, R.J. Neural Smithing: Supervised Learning in Feedforward Artificial Neural Networks; MIT Press: Cambridge, MA, USA, 1999.

86. Tuv, E.; Borisov, A.; Runger, G.; Torkkola, K. Feature selection with ensembles, artificial variables, and redundancy elimination. J. Mach. Learn. Res. 2009, 10, 1341-1366.

87. Kohavi, R.; Sommerfield, D. Feature Subset Selection Using the Wrapper Method: Overfitting and Dynamic Search Space Topology; 1995; pp. 192-197. Available online: https:/ / www.aaai.org/Papers/KDD/1995/KDD95-049.pdf (accessed on 13 July 2021).

88. John, G.H.; Kohavi, R.; Pfleger, K. Irrelevant features and the subset selection problem. In Machine Learning Proceedings 1994; Morgan Kaufmann Publishers: San Francisco, CA, USA, 1994; pp. 121-129.

89. Kohavi, R.; John, G.H. Wrappers for feature subset selection. Artif. Intell. 1997, 97, 273-324. [CrossRef]

90. Mao, K.Z. Orthogonal forward selection and backward elimination algorithms for feature subset selection. IEEE Trans. Syst. Man Cybern. Part B (Cybernetics) 2004, 34, 629-634. [CrossRef]

91. Pham, B.T.; Nguyen-Thoi, T.; Ly, H.B.; Nguyen, M.D.; Al-Ansari, N.; Tran, V.Q.; Le, T.T. Extreme learning machine based prediction of soil shear strength: A sensitivity analysis using Monte Carlo simulations and feature backward elimination. Sustainability 2020, 12, 2339. [CrossRef]

92. Friedman, J.H. Greedy function approximation: A gradient boosting machine. Ann. Stat. 2001, 29, 1189-1232. [CrossRef]

93. Goldstein, A.; Kapelner, A.; Bleich, J.; Pitkin, E. Peeking inside the black box: Visualizing statistical learning with plots of individual conditional expectation. J. Comput. Graph. Stat. 2015, 24, 44-65. [CrossRef]

94. Ly, H.B.; Le, T.T.; Vu, H.L.T.; Tran, V.Q.; Le, L.M.; Pham, B.T. Computational hybrid machine learning based prediction of shear capacity for steel fiber reinforced concrete beams. Sustainability 2020, 12, 2709. [CrossRef]

95. Singh, A.; Kotiyal, V.; Sharma, S.; Nagar, J.; Lee, C.C. A machine learning approach to predict the average localization error with applications to wireless sensor networks. IEEE Access 2020, 8, 208253-208263. [CrossRef]

96. Singh, A.; Nagar, J.; Sharma, S.; Kotiyal, V. A Gaussian process regression approach to predict the k-barrier coverage probability for intrusion detection in wireless sensor networks. Expert Syst. Appl. 2021, 172, 114603. [CrossRef]

97. He, X.; Zhao, K.; Chu, X. AutoML: A Survey of the State-of-the-Art. Knowl.-Based Syst. 2021, 212, 106622. [CrossRef]

98. Neill, S.P.; Hashemi, M.R. Fundamentals of Ocean Renewable Energy: Generating Electricity from the Sea; Academic Press, Elsevier Ltd., 2018. Available online: https:/ / www.elsevier.com/books/fundamentals-of-ocean-renewable-energy/neill/978-0-12-810448-4 (accessed on 13 July 2021).

99. Botchkarev, A. Performance metrics (error measures) in machine learning regression, forecasting and prognostics: Properties and typology. arXiv 2018, arXiv:1809.03006.

100. Yang, Y.; Ye, Z.; Su, Y.; Zhao, Q.; Li, X.; Ouyang, D. Deep learning for in vitro prediction of pharmaceutical formulations. Acta Pharm. Sin. B 2019, 9, 177-185. [CrossRef]

101. Pham, H. A new criterion for model selection. Mathematics 2019, 7, 1215. [CrossRef]

102. Vrieze, S.I. Model selection and psychological theory: A discussion of the differences between the Akaike information criterion (AIC) and the Bayesian information criterion (BIC). Psychol. Methods 2012, 17, 228. [CrossRef]

103. Claeskens, G.; Hjort, N.L. Model Selection and Model Averaging, Cambridge Books; Cambridge University Press: Cambridge, UK, 2008; number 9780521852258, 1-312. Available online: https:/ /ideas.repec.org/b/cup/cbooks/9780521852258.html (accessed on 13 July 2021).

104. Rao, S.S.; Das, S.; Nagaraju, M.; Venugopal, M.; Rajankar, P.; Laghate, P.; Reddy, M.S.; Joshi, A.; Sharma, J. Modified Dubois model for estimating soil moisture with dual polarized SAR data. J. Indian Soc. Remote Sens. 2013, 41, 865-872.

105. Choker, M.; Baghdadi, N.; Zribi, M.; El Hajj, M.; Paloscia, S.; Verhoest, N.E.; Lievens, H.; Mattia, F. Evaluation of the Oh, Dubois and IEM backscatter models using a large dataset of SAR data and experimental soil measurements. Water 2017, 9, 38. [CrossRef]

106. Zhu, L.; Walker, J.P.; Ye, N.; Rüdiger, C. Roughness and vegetation change detection: A pre-processing for soil moisture retrieval from multi-temporal SAR imagery. Remote Sens. Environ. 2019, 225, 93-106. [CrossRef] 